\title{
Denudation processes and rates in the Transverse Ranges, southern California: Erosional response of a transitional landscape to external and anthropogenic forcing
}

\author{
J. Lavé ${ }^{1}$ and D. Burbank ${ }^{2}$ \\ Department of Geosciences, Pennsylvania State University, University Park, Pennsylvania, USA \\ Received 27 January 2003; revised 17 October 2003; accepted 2 December 2003; published 29 January 2004.
}

[1] Quantification of denudation in the Transverse Ranges of California permits reconstruction of spatial and temporal variations in erosion that represent both the response and evolution of interacting hillslopes and channels. On the southern front of the San Gabriel Mountains, observational records of the infilling of debris basins and dams define twentieth-century landscape erosion rates averaging 1.6 and $0.9 \mathrm{~mm} \mathrm{yr}^{-1}$, respectively. Although all major sediment transport occurs during intense winter storms, debris production on hillslopes is greatly enhanced by recurrent fires. Consequently, in this populated region, anthropogenic fires have augmented the natural erosion rates. We perform a global inversion to estimate the role of precipitation intensity, burned areas, and local slope on catchment denudation rates. After subtracting the effects of anthropogenic fires we estimate landscape denudation rates given natural fire ignition rates. Increased fire during the past century has augmented sediment production in debris basins by an average of $\geq 60 \%$, and individual basins show increases up to $400 \%$. To identify the dominant hillslope erosion processes, the volumetric contribution of landslides was estimated using repeat aerial photographs for the same time interval over which the debris basins have been operative. Between 1928 and 1973, landsliding produced only $~ 10 \%$ of the sediment in debris basins. Even in the long term, when infrequent but volumetrically important landslides occur, bedrock landslides appear to contribute a maximum of 50\% to the long-term landscape denudation. Previous mapping of soil slippage in the San Dimas Experimental Forest within the San Gabriel Mountains [Rice et al., 1969; Rice and Foggin, 1971] indicates that shallow landsliding is likely to be the dominant modern hillslope erosion process. When compared to incision rates derived from a fluvial shear stress model and to exhumation rates based on low-temperature thermochronological data [Blythe et al., 2000], modern "natural" erosion rates are comparable to denudation rates since the Pliocene. Comparisons of modern erosion rates suggest that debris production on hillslopes and first-order channels is directly dependent on vegetation cover and precipitation intensity. For higher-order channels (drainage areas $>2 \mathrm{~km}^{2}$ ), only major storms convey the sediments down valley. During the past century, some temporal decorrelation occurs between small-scale and large-scale catchments because hillslopeproduced sediment is stored in second-order and higher channels until major storms mobilize it. Thus the larger fluvial network damps the episodic, fire-induced hillslope sediment pulses that occur within small watersheds. At a longer temporal scale, however, uplift and denudation may have been sustained sufficiently long in much of the San Gabriel Mountains for the topography to reach a macroscale steady state. In contrast to rapidly eroding $\left(\geq 2 \mathrm{~mm} \mathrm{yr}^{-1}\right)$ ranges, for which quantification of bedrock landsliding will approximate the sediment flux, the San Gabriel Mountains occupy a niche of intermediate rates $\left(0.1-1.0 \mathrm{~mm} \mathrm{yr}^{-1}\right)$ in which a broad suite of hillslope processes, including shallow-seated and deep-seated landslides, debris flows, and wet and dry ravel,

\footnotetext{
${ }^{1}$ Now at Laboratoire de Géodynamique des Chaînes Alpines, Grenoble, France.

${ }^{2}$ Now at Department of Geological Sciences, University of California, Santa Barbara, California, USA.
} 
contribute to the sediment flux. INDEX TERMS: 1625 Global Change: Geomorphology and weathering (1824, 1886); 1815 Hydrology: Erosion and sedimentation; 1860 Hydrology: Runoff and streamflow; KEYWORDS: erosion rates, San Gabriel Mountains, hillslope erosion processes, landscape response

Citation: Lavé, J., and D. Burbank (2004), Denudation processes and rates in the Transverse Ranges, southern California: Erosional response of a transitional landscape to external and anthropogenic forcing, J. Geophys. Res., 109, F01006, doi:10.1029/2003JF000023.

\section{Introduction}

[2] The kinematics of mountain building results from the combination of crustal deformation and erosion. In theory, the two processes might be strongly coupled [e.g., Koons, 1989; Molnar and England, 1990; Willett et al., 1993; Anderson, 1994; Avouac and Burov, 1996; Willett, 1999] because denudation partly controls the gravitational forces during mountain building and thus the regional stress regime and, conversely, because the topography created by crustal deformation influences climate and thus the erosion regime. Since Penck's [1953] work, tectonic rock uplift and denudation are commonly considered to tend to balance each other as result of this coupling, introducing the concept of dynamic equilibrium. Such a view is reasonable as long as tectonic forcing can be considered as constant at the timescale necessary to reach the equilibrium [Kooi and Beaumont, 1996].

[3] On the other hand, climatic fluctuations tend to prevent such a steady state and force topography to constantly readjust to changing erosional conditions. Because different elements of the landscape (e.g., hillslope, channel, or fluvial network) have contrasting response times, they are not similarly sensitive to the same climatic cycles. In theory, the notion of dynamic equilibrium for Quaternary times makes sense at timescales of several 100 kyr climatic cycles. However, a better understanding of the sensitivity and amplitude of landscape responses is needed before assessing the timescale for which dynamic equilibrium is relevant.

[4] In this paper we investigate the erosional response of the different landscape elements in the Transverse Ranges of southern California, and we test whether modern erosion rates match those expected for steady state topography. We document the pattern of denudation by analyzing erosion at different spatiotemporal scales. First, we describe the geologic, tectonic, climatic setting, and long-term denudation pattern [Blythe et al., 2000] of the study area that encompasses most of the San Gabriel Mountains. We then present the results of our analysis of the debris basin filling history with respect to different triggering factors, in particular fire history. Subsequently, we attempt to extract the "natural" rate of erosion in the absence of anthropogenic fire. To determine the hillslope processes that produce the observed debris, we mapped landslides that occurred in the same area for the last 60 years and derived corresponding denudation rates. Two processes are, in fact, considered: deep-seated landslides, volumetrically dominated by the largest slides, and shallow landslides or soil slippages. At a broader scale we investigate a potential topographic signature of spatial variations in long-term denudation rates. In particular, we focus on the fluvial network and use a fluvial shear stress model to build a map of estimated fluvial incision rates at the scale of the San Gabriel Mountains. This map permits us to compare fluvial incision with the other estimates of shortterm erosion rates and the long-term denudation rates as deduced from fission track analysis [Blythe et al., 2000]. Finally, we discuss the implications of our different estimates of erosion rates in terms of landscape evolution and dynamic equilibrium.

\section{Overview of Transverse Ranges Tectonics and Climate}

\subsection{Geological and Tectonic Settings}

[5] Since the inception of the Californian transform margin $\sim 20-25$ Myr ago, frequent reorganization of the fault system, combined with lateral extension, has driven spatial variations in the distribution of regional strain [Atwater and Stock, 1998]. Consistent with the overall eastward migration of the dominant transform fault, the modern trace of the San Andreas fault became active 10-2 Ma. In southern California the San Gabriel fault may represent a proto-San Andreas transform fault [Crowell, 1962]. Today, the San Andreas fault system absorbs about two thirds of the relative motion between the North American and Pacific plates. The left-sweeping "Big Bend" in the San Andreas fault causes contraction across this dextral fault in southern California, where modern geodesy defines north-south shortening rates of $\sim 10 \mathrm{~mm} \mathrm{yr}^{-1}$ between the San Andreas fault and the offshore Borderlands [Shen et al., 1996]. This contraction is responsible for the growth of the Transverse Ranges, including the San Gabriel and San Bernardino Mountains, and generates much of the seismic hazard in the Los Angeles basin.

[6] The basement rocks that form the bulk of the San Gabriel Mountains are mostly Precambrian and upper Mesozoic metamorphic and plutonic rocks. The youngest granitic plutons of probable Upper Cretaceous age have intruded mainly Upper Triassic granodiorites and Precambrian gneiss-amphibolite-granite and anorthosite-syenitegabbro complexes. These basement units have been overthrust to the east by the Vincent thrust above the Upper Cretaceous Pelona schist. Minor amounts of Tertiary volcanic and sedimentary rocks are preserved within the San Gabriel Mountains [Barth, 1990].

[7] At the level of the Big Bend the late Quaternary slip rate on the San Andreas fault decreases southeastward from $\sim 35 \mathrm{~mm} \mathrm{yr}^{-1}$ in Wallace Creek [Sieh and Jahns, 1984] to $\sim 25 \mathrm{~mm} \mathrm{yr}^{-1}$ in Cajon Pass [Weldon, 1986]. Extrapolation of these rates to account for observed offsets of 220$260 \mathrm{~km}$ of rock units across the San Andreas fault [Powell, 1981; Hill and Dibblee, 1953] suggests that the modern San Andreas fault was initiated 6-10 Myr ago. Although the late Cenozoic structural history of the San Gabriel Mountains is not well known, contraction across the nascent range and the initial stages of uplift probably began at that 
time, concomitantly with inversion of the Los Angeles basin since $\sim 7 \mathrm{Ma}$ [Bjorklund et al., 2002].

\subsection{Active Tectonics and Its Relation to Present Topography}

[8] The modern topography and relief of the San Gabriel Mountains (Figure 1a) are a response to the sustained late Cenozoic contraction in the region of the "Big Bend." Today, many active faults bound the San Gabriel Mountains. The primarily strike-slip San Andreas fault defines the northern limit of the range. Its southern front is delineated by the segmented, north dipping Sierra Madre-Cucamonga thrust-fault system (Figure 1a). In the east the Cucamonga fault is slipping at a rate of $2-5.5 \mathrm{~mm} \mathrm{yr}^{-1}$ [Morton and Matti, 1987; Petersen and Wesnousky, 1994], whereas the west-central segment of the Sierra Madre fault displays at least two tectonic scarps in the foothills, with one of them slipping at a rate of $0.6 \mathrm{~mm} \mathrm{yr}^{-1}$ [Rubin et al., 1998]. Although the San Gabriel fault was an active strike-slip fault in the past, late Quaternary slip on it is not well defined. West of its junction with the Sierra Madre fault, slip rates may range from $1-5 \mathrm{~mm} \mathrm{yr}^{-1}$ [Petersen and Wesnousky, 1994]. Farther east, offset fluvial terraces in the West Fork of the San Gabriel River suggest a south-side-up component of slip, although apparently unruptured old landslide deposits nearby suggest probable low activity on this fault segment. Whereas several other faults, including the Mint Canyon, Soledad, San Antonio, Stoddard, and Clearwater faults, within the San Gabriel Mountains have apparently experienced Quaternary displacements, their slip rates are presently either unknown and/or likely to be low [Jennings and Charles, 1994].

[9] Modern microseismicity is primarily concentrated along the boundaries of the San Gabriel Mountains. Two $M>5.5$ earthquakes have occurred beneath the range during the second half of the twentieth century: the San Fernando earthquake in 1971, which broke the western segment of the Sierra Madre fault, and the Sierra Madre earthquake in 1991, which ruptured the Sawpit Canyon fault, a northeast trending splay from the central Sierra Madre fault [Hauksson, 1994].

\subsection{Long-Term Denudation Rates}

[10] Recent apatite fission track (FT) and (U - Th)/He analyses [Blythe et al., 2000] have revealed the low-temperature thermal history and Cenozoic denudation history of the San Gabriel and San Bernardino Ranges. In the San Gabriel Mountains, 38 FT ages [Blythe et al., 2000, 2002] range from 3 to $64 \mathrm{Ma}$ (Figure $1 \mathrm{~b}$ ). The FT data indicate three phases of cooling. The oldest phase ranges from 65 and $40 \mathrm{Ma}$ and coincides with the end of Laramide deformation, whereas the second one extends from 17 to $12 \mathrm{Ma}$ in association with a possible extensional regime and related core complexes. At this time the San Gabriel Mountains were probably adjacent to the Chocolate or Orocopia Mountains in extreme southern California [Blythe et al., 2000]. The most recent phase of cooling commences $\sim 5-7 \mathrm{Ma}$, when the Los Angeles basin began to experience compressive and transpressive deformation [Bjorklund et al., 2002].

[11] Following Blythe et al. [2000] and in view of morphology, topography, major faults, and the FT and He ages, we divide the San Gabriel Mountains into five blocks (Figure 1a): the Central Sierra Madre block (CSM); the Eastern Sierra Madre block (ESM); the Mount Baldy and Cucamonga block (MBC); the Tujunga block (TU); and the Western San Gabriel block (WSG). In contrast to Blythe et al. [2000], we split the Sierra Madre block into two blocks at the level of the active Sawpit Canyon fault. We later use these different morphotectonic units to define contrasting rates of debris production by landsliding and as a basis for comparing spatial variations in rates of erosion.

\subsection{Precipitation and Hydrological Characteristics of the Transverse Ranges}

\subsubsection{Precipitation and Vegetation in the San Gabriel} Mountains

[12] Climatic conditions in the Transverse Ranges and Los Angeles basin have been measured extensively during the past century. In the San Gabriel Mountains the Los Angeles County Department of Public Works (LACDPW) and the U.S. Geological Survey (USGS) have monitored more than 50 rain gauges (National Climate Data Center, http://lwf.ncdc.noaa.gov/oa/climate/climatedata.html; http:// dss.ucar.edu/datasets/ds510.0). These daily precipitation measurements yield not only a well-constrained, 100 year average precipitation map (Figure 2a) but define the maximum 24 hour precipitation (Figure $2 b$ ).

[13] The Transverse Ranges receive moisture mostly from the Pacific Ocean to the west and southwest. Typical storm trajectories generate a pronounced rain shadow (the Mojave Desert) in the northeastern part of the San Gabriel and San Bernardino Mountains. From west to east, mean annual precipitation amounts to $600 \mathrm{~mm} \mathrm{yr}^{-1}, 1000 \mathrm{~mm} \mathrm{yr}^{-1}$, and $200 \mathrm{~mm} \mathrm{yr}^{-1}$ in the Los Angeles basin, San Gabriel and San Bernardino high peaks, and Mojave Desert, respectively. Most precipitation falls during winter time between November and March, except in the Mojave, where precipitation may occur mainly during convective summer storms. Despite some disparities, the maximum daily precipitation, as represented by the maximum 24 hour precipitation value over the past 50 years (Figure 2b), displays geographic variations that resemble the average annual precipitation (Figure 2a). Both peaks of annual and maximum daily precipitation are spatially concordant and localized on the well expressed frontal relief of the central Sierra Madre or on the topographic highs of Mount Baldy and the North Fork of the San Gabriel River.

[14] At high elevations in the Transverse Ranges, up to $80 \%$ of the precipitation falls as snow, mainly during winter and spring storms [Minnich, 1986, 1989]. Because snow stored on hillsides does not contribute directly to runoff, we might expect that hydrologic networks with large parts of their catchments at high elevation would display a runoff deficit with respect to short-term precipitation. However, hydrologic data, for example, in the east fork of the San Gabriel River (one of the most elevated watersheds (Figure 1a)), do not display a recognizable deficit. The reason for the absence of a discernable lag is presently unclear. It may result from some combination of the observed rise in the lower limit of snowfall of 300$1000 \mathrm{~m}$ during the heaviest precipitation [Minnich, 1986, 1989] and the ensuing rainfall on snow, causing rapid melting at intermediate elevations. In the following we 
a

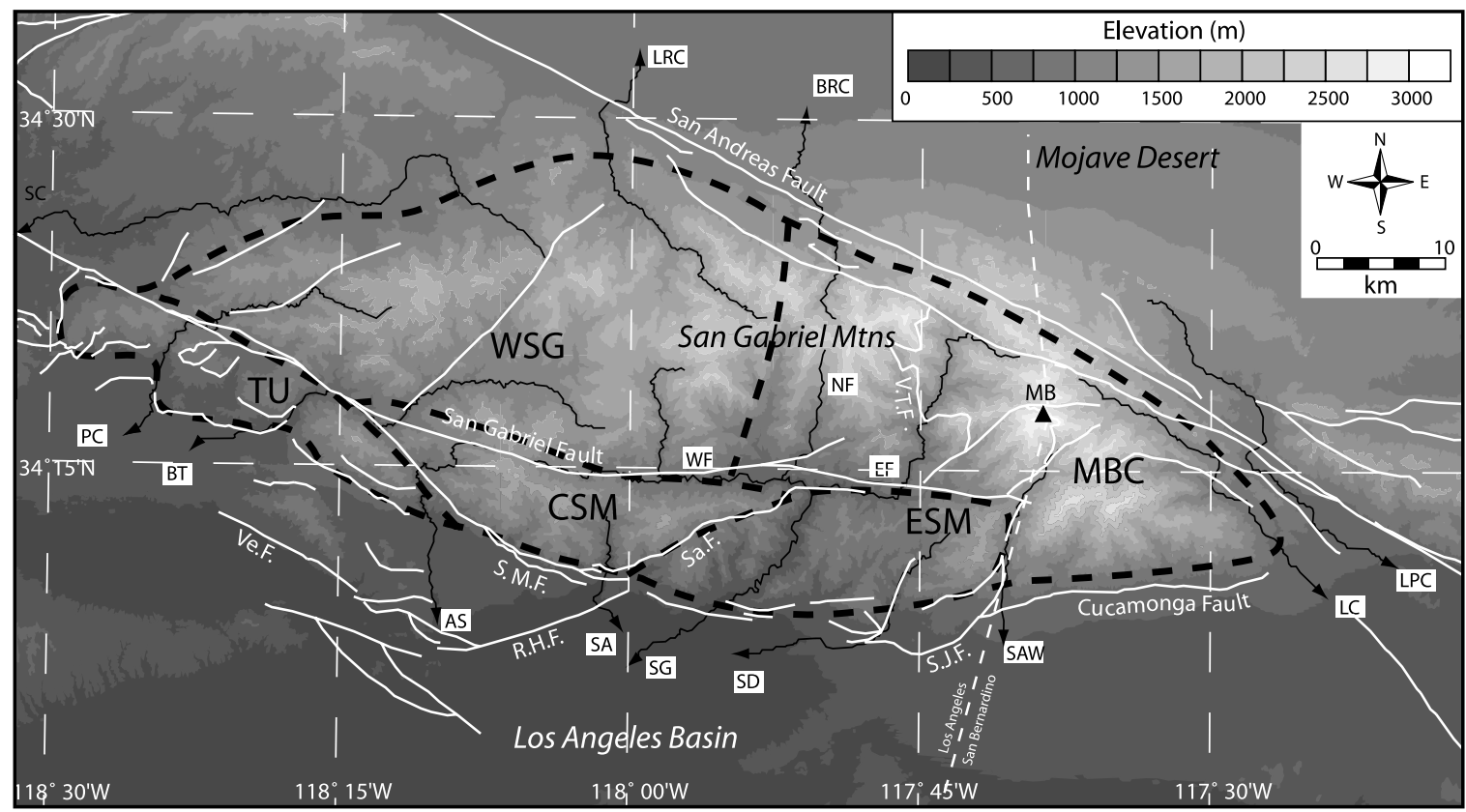

$\mathrm{b}$

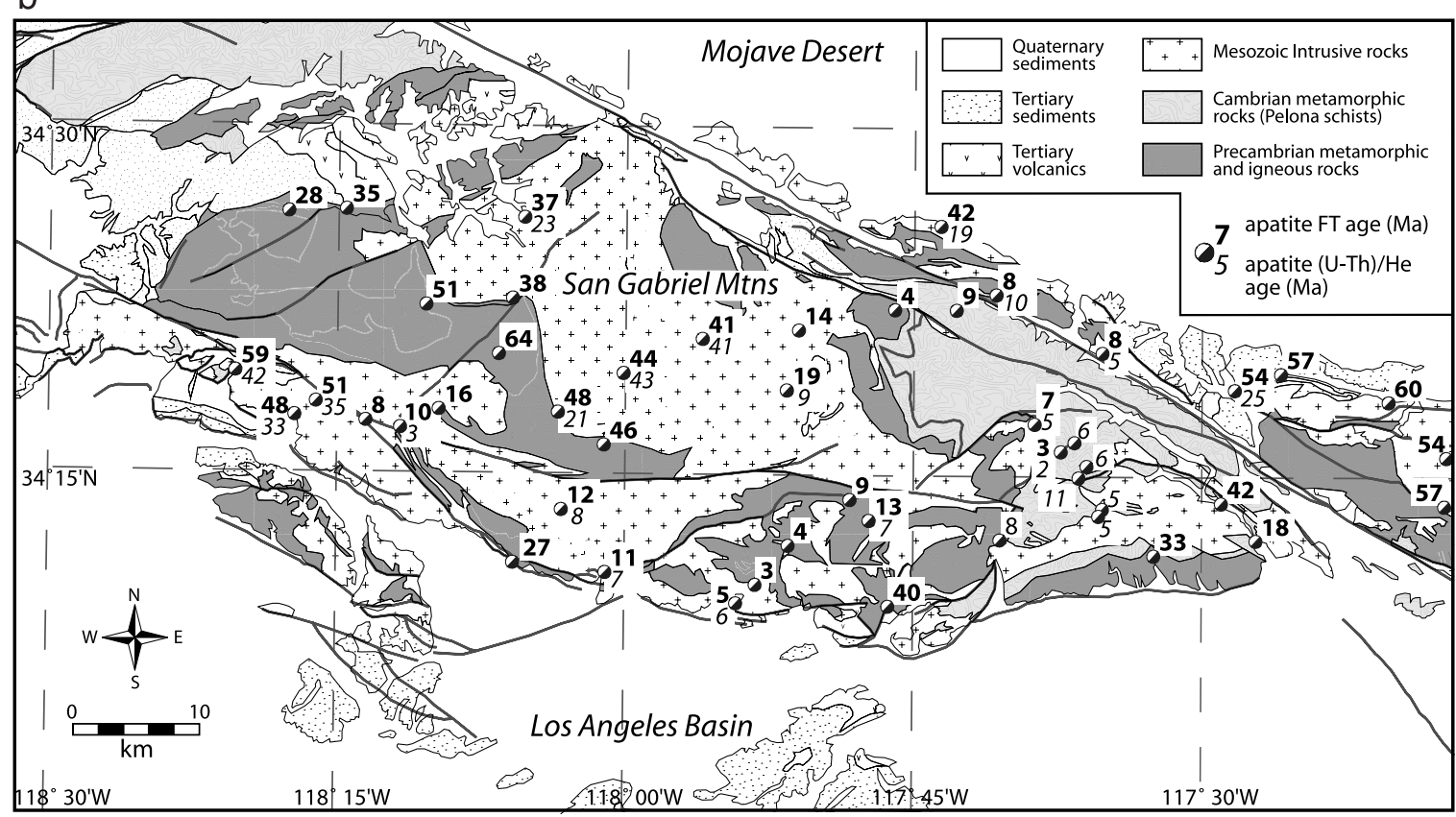

Figure 1. (a) Topographic map of the San Gabriel Mountains with the major faults extracted from a U.S. Geological Survey scale 1:250,000 geological map [Jennings and Strand, 1969]. On the basis of topography, thermochronological data [Blythe et al., 2000] (Figure 1b), and the major faults and tectonic boundaries, the range is divided into five morphotectonic regions to facilitate regional analysis and comparisons of estimates of denudation rates by different methods. CSM, Central Sierra Madre block; ESM, Eastern Sierra Madre block; MBC, Mount Baldy and Cucamonga block; TU, Tujunga block; WSG, Western San Gabriel block; MB, Mount Baldy summit. The major faults are R.H.F., Raymond Hill fault; Sa.F., Sawpit fault, S.J.F., San Jose fault; S.M.F., Sierra Madre fault; Ve.F., Verdugo fault; V.T.F., Vitier Thrust fault. The major rivers are AS, Arroyo Seco; BRC, Big Rock Creek; BT, Big Tujunga; LC, Lytle Creek; LPC, Lone Pine Canyon; LRC, Little Rock Creek; PC, Pacoima Creek; SA, Santa Anita; SAW, San Antonio Wash; SC, Santa Clara; SD, San Dimas; SG, San Gabriel River (EF, east fork; NF, North Fork; WF, West Fork). (b) Main geological units of the Transverse Ranges (scale 1:250,000 geological map) [Jennings and Strand, 1969]. Thermochronological data (apatite fission track (bold) and (U - Th)/He (italic) dates) are reported from Blythe et al. [2000, 2002]. 


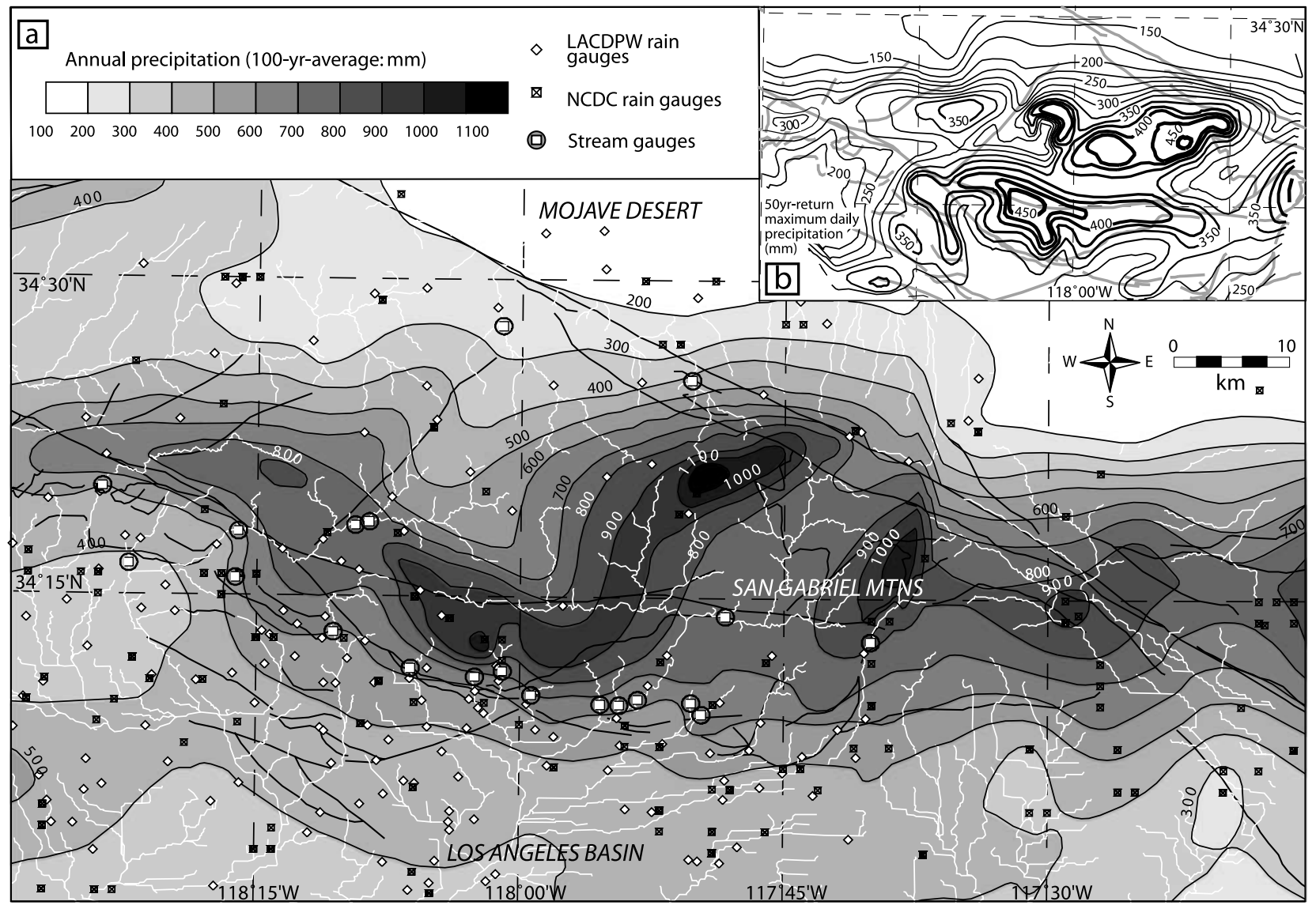

Figure 2. (a) Annual precipitation map of the Transverse Ranges depicting the rain shadow in the Mojave Desert north of the San Gabriel and San Bernardino Ranges. Note the numerous rain gauges and stream gauges on the southern flank of the San Gabriel Mountains used to calibrate a simplified hydroclimatic model (Figure 3). The map synthesizes a 100 year average precipitation map for Los Angeles County (Los Angeles County Power and Water Department, personal communication, 1998) and rain gauge records in San Bernardino County. Also displayed are rain gauge locations for which daily precipitation records (obtained from the National Climate Data Center and LACPWD) were used to analyze hillslope responses to precipitation intensity and to fire effects. (b) Map of maximum 24 hour precipitation with a 50 year return period in Los Angeles County [LACDPW, 1991]. Note that peaks of annual and maximum daily precipitation are spatially coincident for the eastern Sierra Madre, Mount Baldy, and the North Fork of the San Gabriel River.

assume that the hydrologic regime is insensitive to differences between rain and snow precipitation.

[15] Vegetation in the San Gabriel Mountains displays striking altitudinal and latitudinal variations. Presently, woodlands, including sycamore, oak, and pines, are preferentially encountered at moderate to high elevation or along river thalwegs. At lower elevation, shrubs, such as chaparral, sage, and chamise, cover the hillslopes. Although both soil characteristics and vegetation cover can influence erosion, we will assume that at the scale of the San Gabriel Mountains, hillslope erosion is weakly sensitive to such variations.

2.4.2. River Network, Hydrologic Regime, and Simplified Hydroclimatic Model of the San Gabriel Mountains

[16] The river network geometry of the San Gabriel Mountains is strongly influenced by climate and tectonics. A marked asymmetry exists between a well-developed southward draining network and a narrow northward draining network: The drainage divide lies well north of the center line of the range. This geometry probably results in part from the asymmetry of precipitation and the rain shadow (Figure 2). The southern network is dominated by the San Gabriel River watershed, which represents a $550 \mathrm{~km}^{2}$ drainage area. In the west the Big Tujunga River, the second largest river in the San Gabriel Mountains, has a $300 \mathrm{~km}^{2}$ catchment. Both networks have been strongly influenced by the San Gabriel fault: The East and West Forks of the San Gabriel River are clearly controlled by this fault (Figures 1a and 2a). The Big Tujunga River displays a $10 \mathrm{~km}$ right step at the fault, perhaps revealing a lithologic guide or an offset produced when the San Gabriel fault was probably still active during the Pliocene.

[17] As seen in most Mediterranean-type climates, the hydrologic regime in the Transverse Ranges displays marked seasonal contrasts. During much of the year, water 
discharge is extremely reduced. Even the San Gabriel River almost dries up in summer. In contrast, after the heaviest storms, major floods are generated, usually lasting 1 or 2 days before decreasing rapidly.

[18] For many decades, numerous stream gauges have been monitored by both the USGS (data is available from http://nwis.waterdata.usgs.gov/usa/nwis/discharge) and the LACDPW (personal communication, 1998) (Figure 2a) in the Transverse Ranges and provide both daily discharge and yearly maximum instantaneous discharge. Stream and rain gauge data have been used to calibrate a semiempirical model for runoff prediction [ $L A C D P W, 1991]$ as a function of rain duration and intensity, hillslopes, and vegetation cover. In the present study we have derived a simpler model that ignores vegetation effects, in part because we are concerned with long-term discharges spanning multiple climate cycles. Because the available daily discharge data preclude deterministic modeling of exact storm responses, we focus on the average response to a uniform rain for 24 hours. In this study we are mostly interested in the peak flows and heaviest storms. Because such flows usually occur when soil infiltration capacity has been reduced following 3-4 days of precipitation, short-term rain intensity is a less important factor.

[19] To test the relationship between precipitation and discharge, we have considered only undammed catchments (for example, the San Gabriel Asuza stream gauge before 1934-1939). The 10-year-return daily discharge is well fit by a simple power law of the drainage area (Figure 3 ). In order to test the sensitivity of the geographic distribution of the precipitation, we also normalized the decadal flood both by the annual precipitation falling on the watershed and by the 50-year-return maximum daily precipitation (Figure 3 ). The best correlation is obtained for the normalization by the annual precipitation. However, the coefficients of correlation are not significantly different (between $0.91<r<0.96$ ). In section 5.2 we utilize the simplified hydroclimatic model

$$
Q_{10} \propto A^{0.92} \bar{P}
$$

where $\bar{P}$ is the mean annual precipitation over the watershed and $A$ is the drainage area.

\section{Short-Term Landscape Denudation Along the Southern Front of the San Gabriel Mountains}

\subsection{Debris Production in Debris Basins and Dams}

[20] For 60 years the LACDPW has been monitoring debris basins in the southern foothills of the San Gabriel Mountains in order to protect inhabitants and buildings from

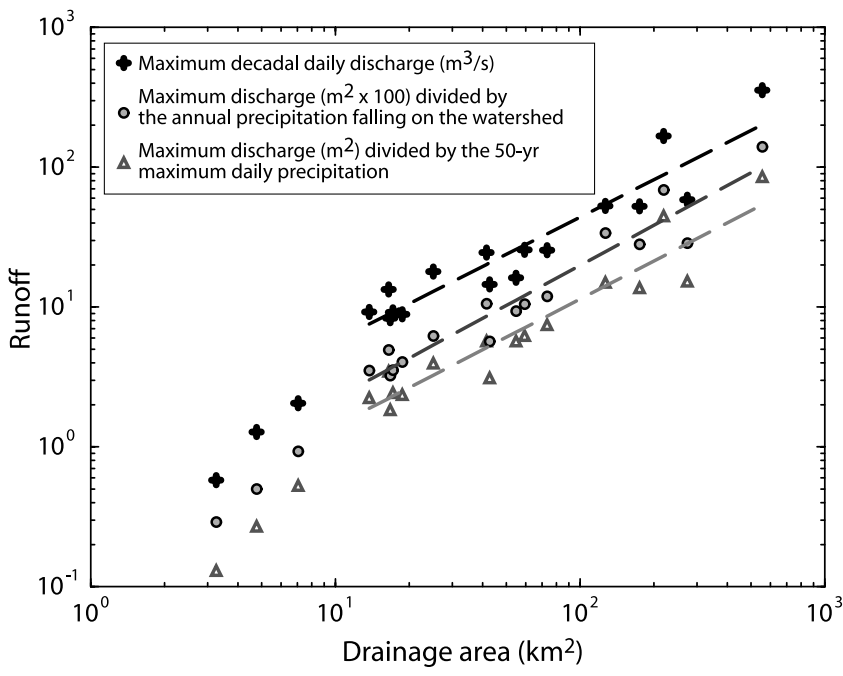

Figure 3. Runoff parameters plotted as a function of drainage area for 20 gauged catchments (Figure 2): decadal maximum flood daily discharge (crosses); decadal maximum discharge divided by the runoff produced by either the annual precipitation falling on the watershed (circles) or by the 50-year-return maximum daily precipitation (squares). The best correlation $(r=0.96)$ is obtained for normalization by annual precipitation (circles), although no significant difference in misfit can be noted.

recurrent mudflows and debris flows initiated during winter storms. During recent decades, as the city has grown and encroached progressively on the range front, the number of debris basins has expanded to the present 115 basins in Los Angeles County (Figure 4). After each major winter storm the debris basins are inspected, and whenever filling exceeds $25 \%$, the sediments are removed by truck. Using a rapid geodetic survey or by weighing the trucks (mostly for the last 10 years), the LACDPW has been able to track sedimentary volumes deposited in the debris basins. Despite their discontinuous nature, these records represent a unique data set of debris production in an active mountain area. Previous study of these data has been done by Taylor [1981] but at the scale of the whole of southern California.

[21] In our study we compiled the complete data set of 75 range front debris basins in order to estimate sediment production in these small watersheds $\left(A=0.05-8 \mathrm{~km}^{2}\right)$. We assessed sediment production within the range at a larger scale by looking at 12 reservoirs monitored by the LACDPW where either variations in lake bottom topography have been surveyed or sediment fluxes were measured

Figure 4. Debris basins, dams, and their associated watersheds (see Table 1 for code identification). The debris basins lie mostly along the southern front of the San Gabriel Mountains, where some watersheds contain numerous check dams. (a) Polygons display the zones where landslide mapping and analysis were conducted, i.e., on $60 \%$ of the San Gabriel Mountains from four sets of aerial photos: 1928, 1938, 1952-1954, and 1973. Two older landslides and their deposits in the North Fork of the San Gabriel River [Morton et al., 1989] have also been reported (hachured area) and provide an idea of the largest size of documented landslides in that area. The area affected by coseismic landslides during the $M=6.5$ San Fernando 1971 earthquake, as mapped by Morton [1975], is also shown in the western San Gabriel Mountains (gray hachured area). (b, c) Closeups of the southern front of the San Gabriel Mountains. Figure 4c also shows a closeup of the Big Dalton and San Dimas watersheds, where the location of a study on shallow landslides in Bell Canyon [Rice et al., 1969] and denudation rate measurements (crosses) with cosmogenic nuclides [Heimsath, 1999] are represented. 

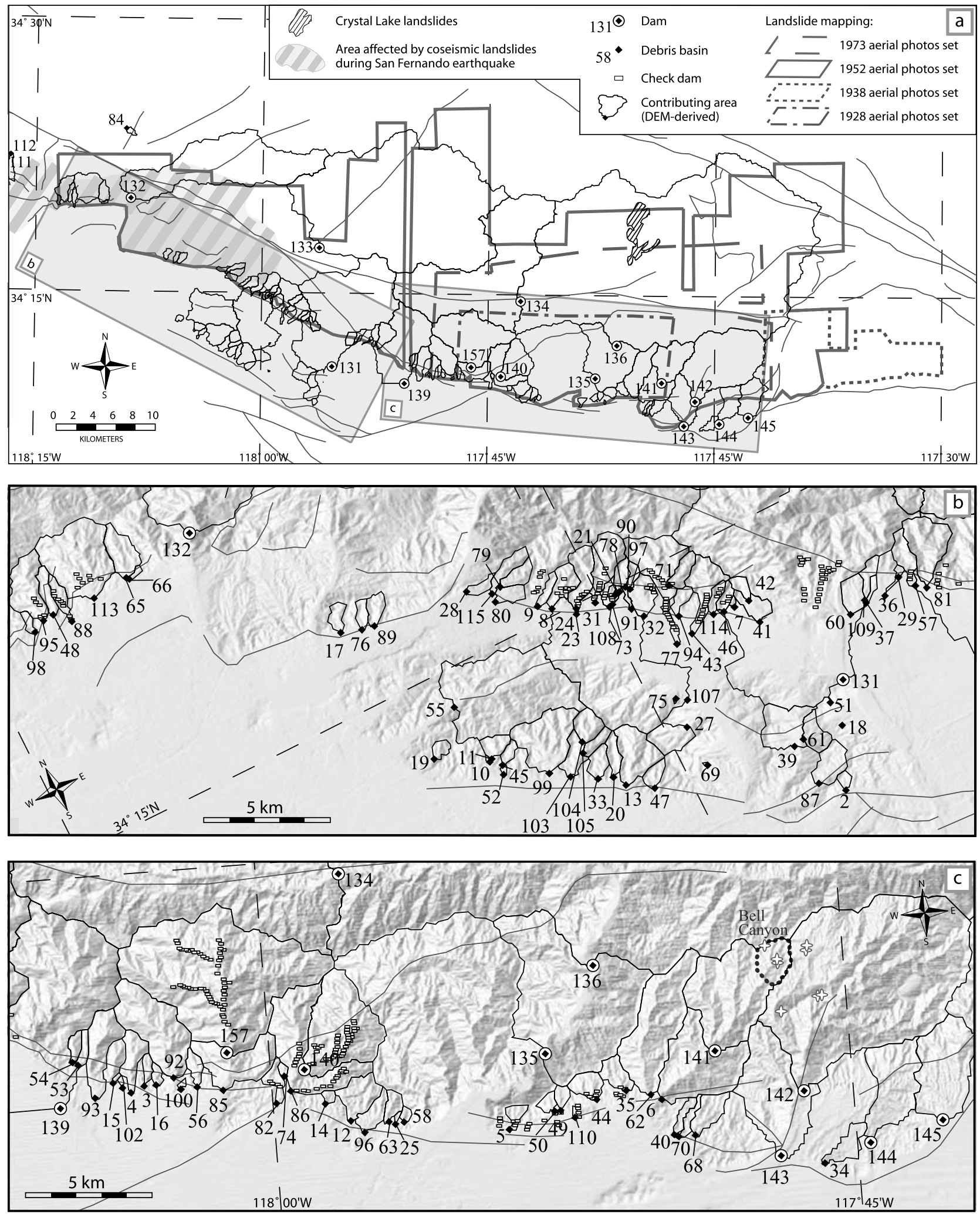


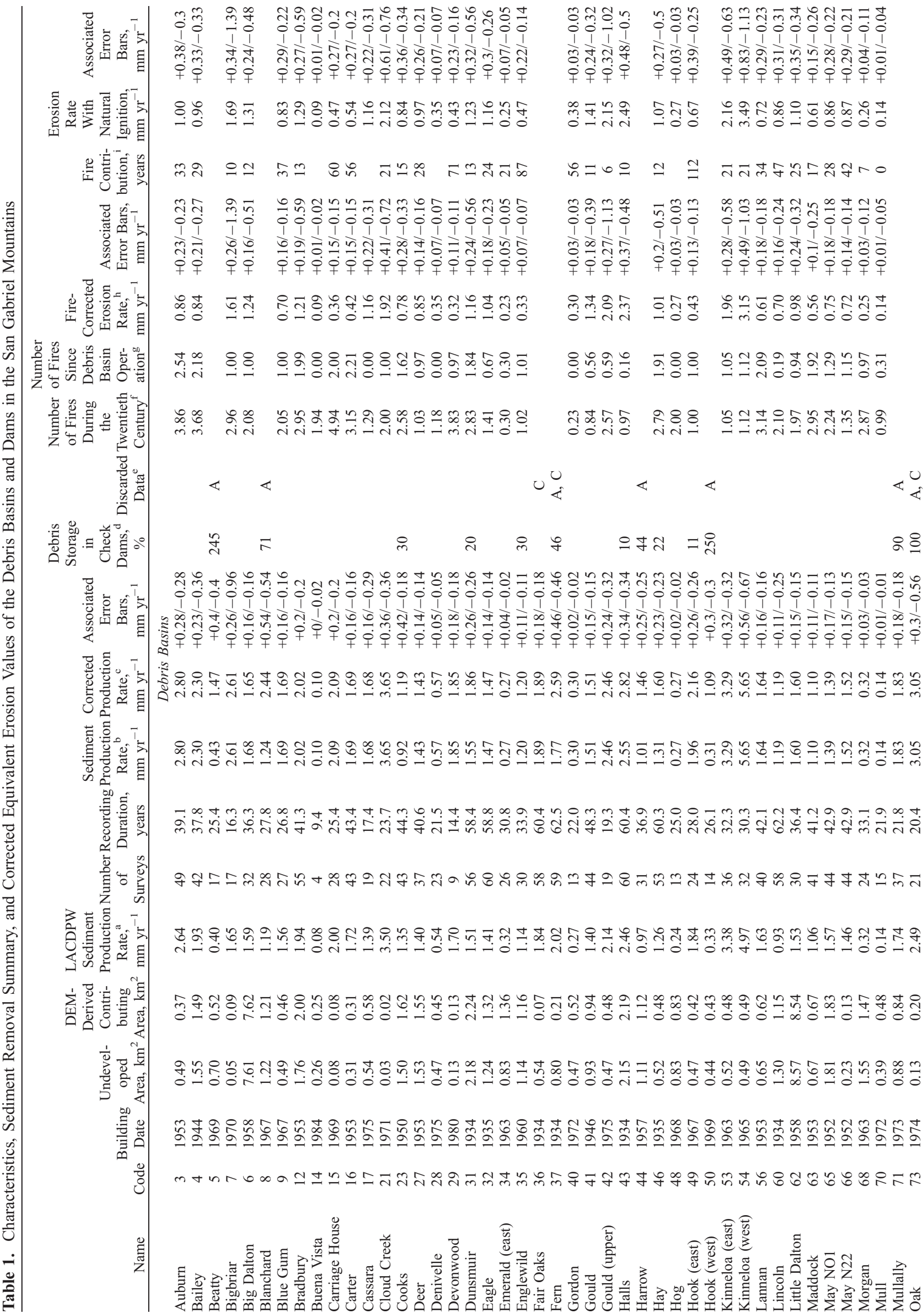




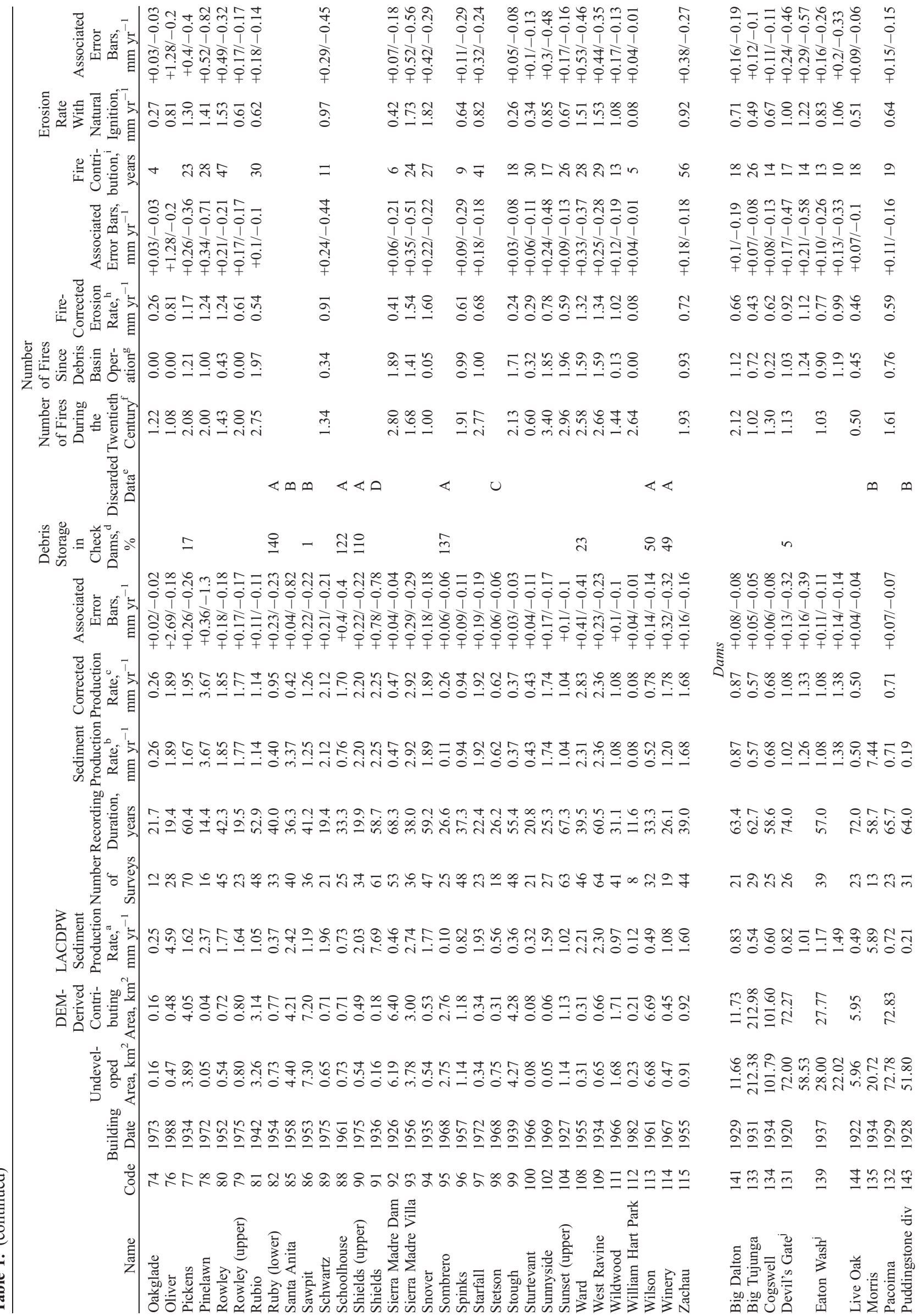




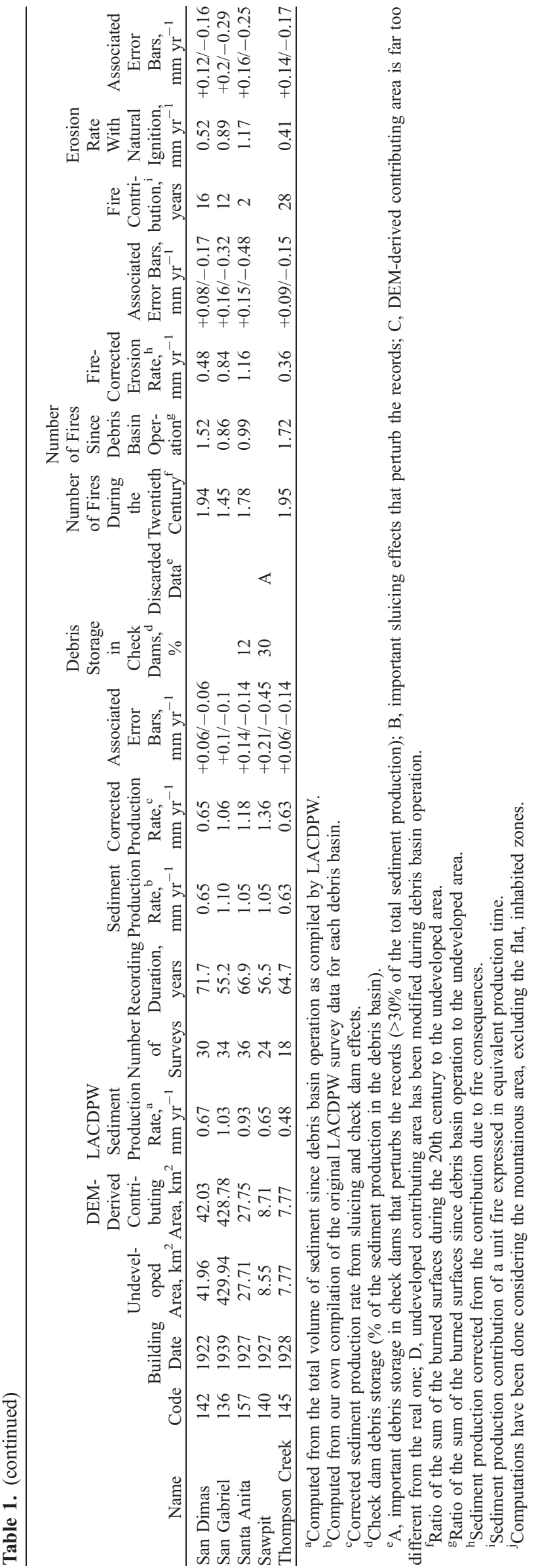

during sluicing operations. The two sets of data (Table 1) define the volume exported by erosion from the San Gabriel Mountains and yield average bedrock denudation after correction for the average porosity of these sediments.

[22] There is, however, no uniform correction for dry sediment density. Several boreholes in sediments behind dams indicate dry sediment densities between 1700 and $2250 \mathrm{~kg} \mathrm{~m}^{-3}$ with little or no depth dependence (LACDPW, personal communication, 1998). For the San Gabriel dam, however, Taylor [1981] reports a lower value of $1590 \mathrm{~kg} \mathrm{~m}^{-3}$. For the sake of simplicity we apply a single value for density. Because the material that fills dams is volumetrically much greater than that from debris basins, an average density of $1900 \mathrm{~kg} \mathrm{~m}^{-3}$, corresponding to a porosity of $30 \%$, has been chosen. We are aware that such a simplification probably overestimates sediment production in many debris basins.

[23] Before analyzing these erosion rates, it has been necessary to apply three additional corrections that account for (1) the contribution of check dams upstream of the debris basin; (2) the actual contributing area subjected to erosion; and (3) any sluiced sediment coming from a potential upstream dam. In order to restrain potential debris flows and trap part of the sediments, the LACDPW built numerous check dams several meters high during the 1960s and 1970s (up to 30 check dams in the Santa Anita watershed, for example (Figure 4c)). Most of these check dams were completely filled when they were resurveyed in the mid1970s. We assume that, presently, all of them have been filled (on average, check dams were $70 \%$ filled within $\sim 10$ years in the San Gabriel Mountains). These check dams occur in $\sim 30 \%$ of the watersheds contributing to debris basins. The volume trapped in the check dams can represent up to $200 \%$ of the cumulative deposition in the debris basin Therefore to improve estimates of denudation rates, we added the contribution of the check dams to debris production in debris basins. Because the temporal evolution of filling these check dams is unknown, however, when we examine the correlation of storm history and debris production, we systematically discard all watersheds with a check dam contribution $>30 \%$.

[24] A correction for the contributing area was applied when the downstream part of the watershed lies beyond the mountain front. If we exclude reincision of previously deposited sediments or, conversely, sediment deposition in the highly urbanized foreland basin, this downstream area has minimal impact on average debris production. To derive a relevant erosion rate, the contributing area was restricted to the mountainous area (Table 1, Figure 4). Contributing area corrections were also applied when part of the watershed is dammed farther upstream. In that case, erosion rate calculations were restricted to the active sediment-contributing area downstream of the dam. The debris trapped in these upstream dams is sometimes sluiced, in which case the sluiced volumes are subtracted from debris production in the lower dam or debris basin.

[25] After correction, some watersheds with both low debris production and numerous check dams yield erosion rates in better agreement with those of their neighbors. However, corrected erosion rates still vary by two orders of magnitude, ranging from 0.08 to $5 \mathrm{~mm} \mathrm{yr}^{-1}$ (Figures 5 and 6). This scatter primarily affects debris basins: The shorter the duration of the record and the smaller the 


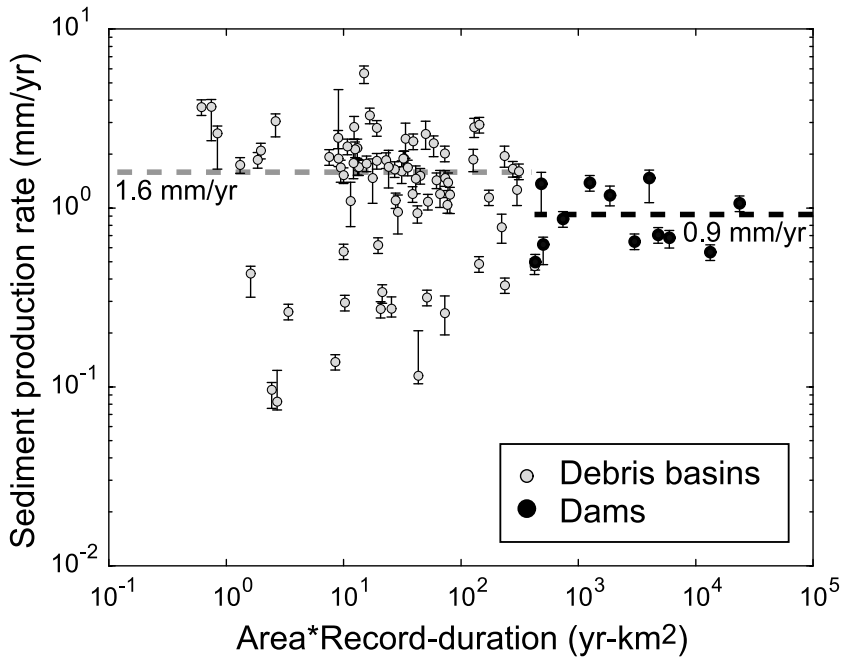

Figure 5. Debris basin (gray circles) and dam (black

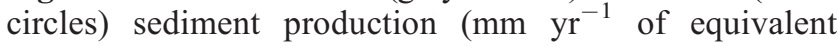
bedrock denudation) after corrections for sluicing, intermediate storage in check dams, and drainage area adjustment. Note that these are plotted as a function of the product of the drainage area and the duration of monitoring in order to emphasize the smoothing effect of either long records and/or large basins. In comparison to catchments with dams, small watersheds with debris basins yield both more scattered rates and higher average sediment production values (almost 2 times higher).

contributing area, the greater the scatter. Average values of debris basins and dams also display a noticeable difference: Erosion rates derived from debris basins average $1.6 \mathrm{~mm} \mathrm{yr}^{-1}$, whereas those from dammed watersheds average only $0.9 \mathrm{~mm} \mathrm{yr}^{-1}$ (Figure 5). As mentioned earlier, this difference could be partly due to the choice of a single sediment density for conversion to equivalent bedrock erosion: Changing the specific weight of the material trapped within debris basins from $1900 \mathrm{~kg} \mathrm{~m}^{-3}$ to $1500 \mathrm{~kg} \mathrm{~m}^{-3}$ would explain almost $50 \%$ of the difference.

[26] Temporary sediment storage in terrace deposits could also contribute to this difference. Many old terraces can indeed be observed along the major rivers, in particular along the San Gabriel and Tujunga Rivers. However, we did not note any general tendency toward continued aggradation along the modern fluvial network. In the North Fork of the San Gabriel River, for example, the last major infilling event has been dated around $7 \mathrm{kyr}$ ago (terrace $\mathrm{T} 7 \mathrm{in}$ Bull [1991]). Since that time, the rivers have tended to degrade [Bull, 1991]. Even during the twentieth century, the geometry of fill behind check dams displays equilibrium aggradational gradients (gradients sufficient to transport all sediment supplied to the site) generally $30 \%$ lower than initial river gradients before damming (LACDPW, personal communication, 1998). Conversely, reincision of terrace material could increase the measured sediment discharge and also bias erosion rate estimates. Our observations on aerial photos do not indicate, however, a higher density of freshly eroded scars in these terrace deposits than in the rest of the landscape. Similarly, reincision of the terrace T7 in the North Fork of the San Gabriel River since its abandon- ment around 4 kyr ago [Bull, 1991] yields a maximum volume of $0.04 \mathrm{~km}^{3}$ and a contribution to the sediment production of $\sim 0.15 \mathrm{~mm} \mathrm{yr}^{-1}$, i.e., an order of magnitude lower than the sediment production rates during the last century. At this stage of the discussion, therefore, we suspect that the data scatter and the difference observed between debris basins and dams arises from geographical or physical differences in erosion.

\subsection{Triggering Factors of Debris Production}

[27] Although debris production surveys are irregular and discontinuous, they usually occur a few days or weeks after major winter storms. Consequently, in most cases, filling events can be linked to climatic events. The contrasting response to precipitation is well illustrated by two watersheds: the Auburn debris basin and the San Gabriel dam (Figure 7). For the San Gabriel dam the six largest filling events follow the six heaviest daily precipitation events (dashed line on Figure 7). By contrast, for the Auburn debris basin, both variables are much more weakly correlated: The six heaviest daily rainfalls were followed by only one major filling event. Such contrasts may be understood when the influence of fire is taken into account. As recognized long ago in the San Gabriel Mountains and, more generally, in California [e.g., Los Angeles County Flood Control District (LACFCD), 1959; Booker et al., 1993; Benda and Dunne, 1997a, 1997b], sediment production after a fire increases dramatically. Both dry ravel after a fire and soil exposure to heavy and even moderate precipitation after fires that burn vegetation and reduce root strength contribute to this increase. As observed in the Auburn debris basin record, even a moderate winter storm that follows a fire, as occurred in 1978 or 1993, can effectively trigger sediment deposition in a debris basin (Figure 7).

[28] Chaparral possesses seeds that are resistant to fire and can regrow quickly: 5 years after a fire, chaparral already provides effective protection against soil erosion, and after 10 years, vegetation cover has returned to previous conditions [LACFCD, 1959] (section A1 and Figure A1). As observed in Figure 7, the 5 years following a fire are the most critical for sediment production.

[29] While the debris basins were operative during the twentieth century (Table 1), the southern front of the San Gabriel Mountains has been burned with a higher frequency than the interior of the range (Figure 6). We would therefore expect higher sediment production in the debris basins than behind the dams, which are in more interior positions. Indeed, debris production is $70 \%$ higher in the debris basins (Figure 5), suggesting a nearly twofold increase of erosion as a consequence of repeated twentieth century fires.

[30] We want to determine whether present erosion rates are also representative of late Holocene rates. Because fire typically enhances erosion, we must first determine whether the present fire regime is natural. Despite attempts to control fires during the past century, fire ignition rates are probably much higher than natural ones due to human-related fires. Even before the Spanish colonization of California, fire regimes were probably influenced by Native Americans for $10 \mathrm{kyr}$ [Aschmann, 1959]. We can gain some insight on natural fire ignition rates by lightning through comparisons with other areas. For example, northern Baja California 


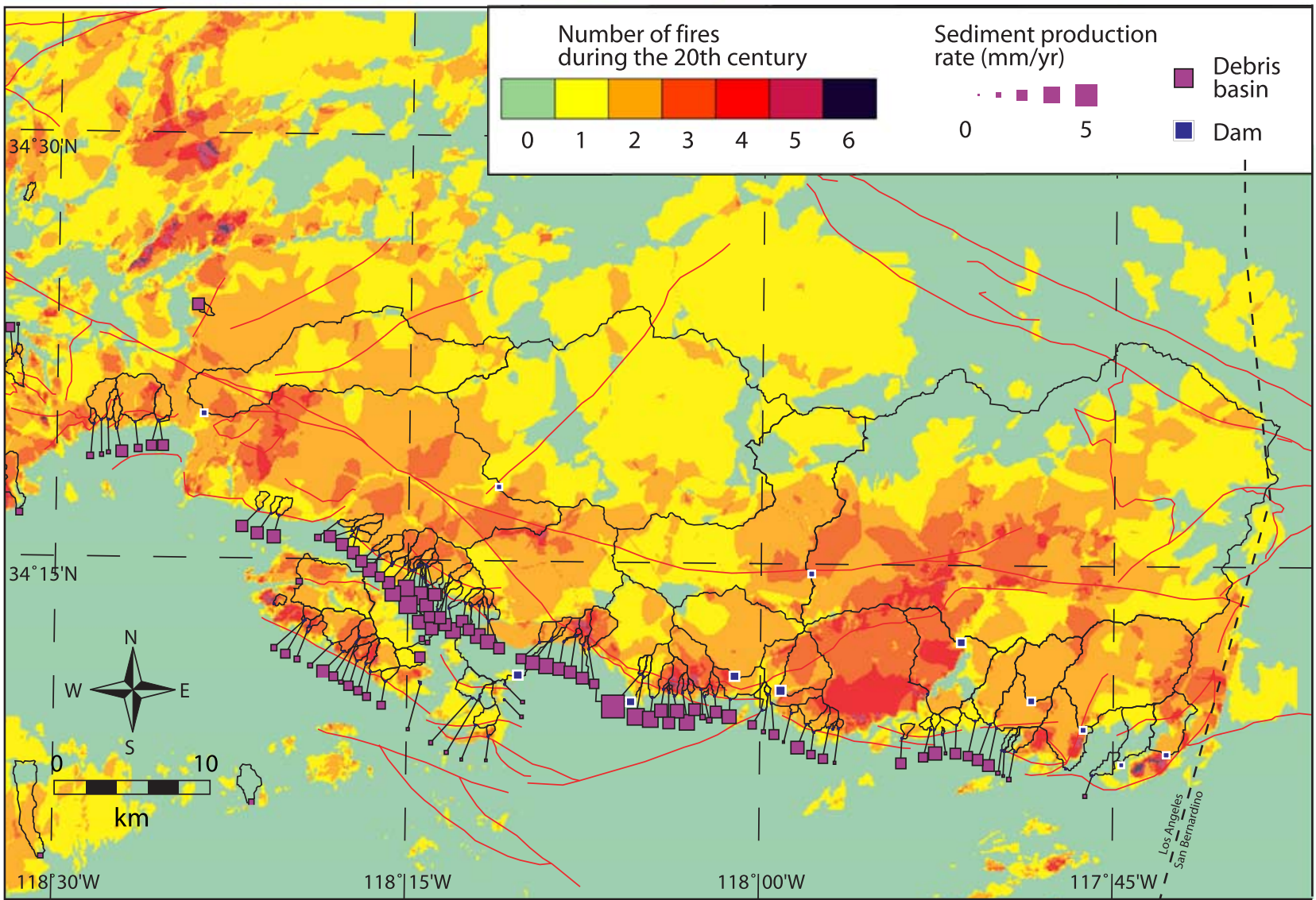

Figure 6. Map of the fire history since 1900 (compilation of annual records courtesy of LACPWD). The southern part of the San Gabriel Mountains has been more frequently burned (for several places, up to six fires in one century) than the rest of the range. Sediment production at debris basins and dams (purple and blue squares, respectively) in the San Gabriel Mountains is represented by symbol sizes proportional to the production rate. Because the record duration in many debris basins is significantly shorter than 100 years, production rates cannot be directly related to the number of fires during the past century on the map.

displays an average return period of fire by natural ignition of 60-80 years [Minnich and Chou, 1997], whereas charcoal frequencies in lacustrine or fluvial sediments suggest an average return period of 250 years in Oregon [Long, 1996] and 350-500 years in Yellowstone [Millspaugh et al., 2000]. Because the natural fire frequency in the San Gabriel Mountains was probably much lower than the present return interval of $\sim 20$ years, anthropogenic fires are likely to have significantly enhanced twentieth century debris production.

[31] In order to derive "natural" erosion rates, we also investigated other anthropogenic sources of sediment, in particular enhanced sediment production by road building. In the absence of detailed records for sediment disturbance by road building we examined potential correlations between sediment production and road density as measured on scale 1:30,000 maps. About half of the watersheds above the debris basins are free of asphalt or dirt roads; the other half is characterized by road densities ranging between 0.5 and $2.5 \mathrm{~km} \mathrm{~km}^{-2}$. Statistically, no difference exists between the watersheds with or without roads $\left(1.45 \pm 0.7 \mathrm{~mm} \mathrm{yr}^{-1}\right.$ and $1.8 \pm 1.2 \mathrm{~mm} \mathrm{yr}^{-1}$, respectively). Whereas this coarse analysis does not account for the exact chronology of road building relative to debris basin operations, the lack of apparent correlation between both variables suggests that sediment production due to road building is insignificant in comparison with fire-related sediment production.

[32] In our subsequent attempt to derive "natural" erosion rates we therefore ignore road building and focus on corrections for debris production due to human-related fires. To do that, we will first remove the estimated contribution of all fires and then add an average contribution due to natural fire.

\subsection{Fire Contribution to Sediment Production}

[33] Based on a 20 year debris basin record, empirical analysis $[L A C F C D, 1959]$ indicates that sediment production, $\left(q_{S}\right)$, depends mainly on storm intensity $I$ (24 hour precipitation value), relief ratio, $R$ (catchment relief/catchment length), and a vegetation index, Ve, according to

$$
q_{S} \propto \frac{R^{0.72} I^{1.67}}{(V e+5)^{2.67}} .
$$

The vegetation index varies between 4 just after a fire and 19-22 [LACFCD, 1959] for normal vegetation cover 5-10 years later (see Figure A1 in Appendix A). 


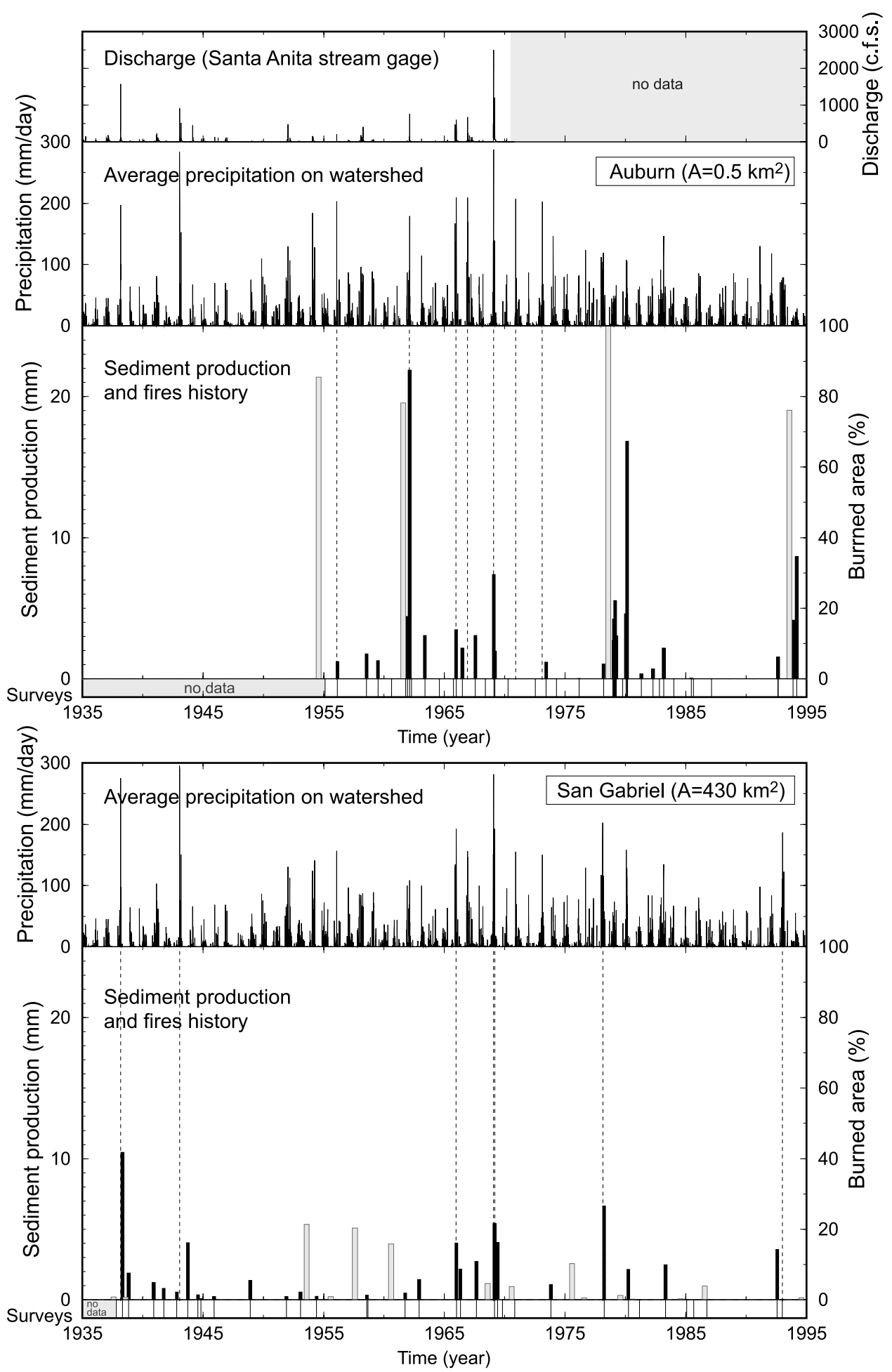

Figure 7. Sediment production (black bars) as a function of fire history (gray bars), precipitation, and flooding for two different watersheds. (top) Representative data for small watersheds: precipitation in the adjacent Auburn catchment $\left(0.5 \mathrm{~km}^{2}\right)$, percentage of the catchment burned, and sediment production for the Auburn debris basin, including discharge, for the contiguous Santa Anita watershed $\left(28 \mathrm{~km}^{2}\right)$. Maximum sediment production occurs principally following major fires and after the major 1969 storm and flood event. (bottom) Analogous data for a large watershed (the San Gabriel catchment: $430 \mathrm{~km}^{2}$ ). Sediment production appears strongly correlated to major storms but relatively independent of fire occurrence. This clearly indicates a different response of the large watersheds to fire and climate forcing, probably related to the unlikelihood of burning the entire catchment and to the damping effect of the sediment transport processes in the more extended fluvial network. In both sediment production diagrams, vertical dashed lines indicate the seven largest daily precipitation events during debris basin or dam operation. 
[34] Only 2 decades of data from a few debris basins define relation (2). Using the more extensive, present database, we performed an inversion on the above parameters for the debris basins with upstream catchments of $<2 \mathrm{~km}^{2}$. The best estimate of sediment accumulation in debris basin $j$ during the period of time between two successive LACDPW surveys at times $t_{i}$ and $t_{i+1}, Q_{S}^{i, j}$, was obtained applying a steepest descent algorithm (Gauss-Newton method [Tarantola, 1987]) on the relation

$$
Q_{S}^{i, j}=\alpha_{0} \int_{t_{i}}^{t_{i+1}} \iint_{A_{j}} \frac{S(\mathbf{x})^{\alpha_{1}}\left(I(\mathbf{x}, t)+\alpha_{2}\right)^{\alpha_{3}}}{\left(V e(\mathbf{x}, t)+\alpha_{4}\right)^{\alpha_{S}}} d \mathbf{x} d t
$$

in order to minimize the misfit function

$$
S_{\Sigma}=\sum_{j=1}^{j=N} \sum_{i=1}^{i=n_{j}}\left(Q_{d b}^{i, j}-Q_{S}^{i, j}\right)^{2},
$$

here $A$ is the drainage area, and $S(\mathbf{x})$, is the average hillslope angle (calculated on $90 \times 90 \mathrm{~m}$ cells) in a point $\mathbf{x}$ of the catchment. $S(\mathbf{x})$ replaces the relief ratio $R$ with a local topographic parameter. On the basis of the fire history and vegetation regrowth relationship (Figure A1), a vegetation index has been computed for each debris basin and dam during its operative lifetime. The runoff parameters $\alpha_{2}=2 \pm$ $10 \mathrm{~mm}$ and $\alpha_{3}=1.7 \pm 0.2$ are found to be in good agreement with $L A C F C D$ 's [1959] relationship (1). The two vegetation cover parameters that minimize the misfit function, $\alpha_{4}=$ $7.5 \pm 1.5$ and $\alpha_{5}=3.4 \pm 0.3$, are substantially different from equation (3), but they lead to roughly similar dependency for $4 \leq \mathrm{Ve} \leq 20$. More surprisingly, the slope exponent of $\alpha_{1}=$ $0.0 \pm 0.2$ indicates that local slope plays no significant role in erosion intensity. Relation (3) assumes the same slope dependency for soil erosion either after a fire or with a normal vegetation cover. However, physical erosion processes in each case are probably very different: erosion through dry ravel, rain splash, and gullying in the first case and predominantly shallow landsliding in the second case. Distinct slope dependency, related to these different erosion processes, could thus lead to this counterintuitive result after inversion of the debris basin accumulation history. More generally, we note that the poor rms,

$$
\frac{\sqrt{S_{\Sigma}}}{\sum_{j=1}^{j=N} n_{j}} \cong 3 \mathrm{~mm},
$$

indicates either that functional relationships like equations (2) or (3) are inadequate to define sediment accumulation fully or that other key variables, such as erosional sensitivity to instantaneous peak precipitation rather than to the daily average value, are not included in these equations. In addition, the vegetation index and the rate of vegetation regrowth (Figure A1), as applied to the study of hillslope responses to fire and climatic forcing, do not capture the more complex evolution of the root systems and their role in anchoring soil cover and in preventing soil slippage.

[35] With these limitations in mind, but lacking a more adequate relation, we have used equation (3) to derive a zero-order estimate for the contribution of fire to sediment production, the erosion rate in absence of fires, and the erosion rate including the natural fire ignition rate. To perform these corrections on the raw data, we take advantage of the general form of relation (3) to predict that sediment production in a debris basin, $q_{B}$, in the absence of fires would have been

$$
q_{B}=\alpha_{0} \iint_{A} \frac{S(\mathbf{x})^{\alpha_{1}}\left(I(\mathbf{x})+\alpha_{2}\right)^{\alpha_{3}}}{\left(20+\alpha_{4}\right)^{\alpha_{5}}} d \mathbf{x}
$$

[36] Given the weak dependency of the local erosion relative to the local slope $\left(\alpha_{1} \cong 0\right)$, the slope variable can be neglected, and the accumulated sediment production $Q_{B, j}$ in the absence of fires can be approximated from the observed debris production $Q_{S, j}$ between two surveys in a debris basin at times $t_{i}$ and $t_{i+1}$ following

$$
\begin{aligned}
Q_{B, j}= & Q_{S, j}\left(\int_{t_{i}}^{t_{i+1}} \iint_{A} \frac{\left(I(\mathbf{x}, t)+\alpha_{2}\right)^{\alpha_{3}}}{\left(20+\alpha_{4}\right)^{\alpha_{5}}} d A d t\right. \\
& \left./ \int_{t_{i}}^{t_{i+1}} \iint_{A} \frac{\left(I(\mathbf{x}, t)+\alpha_{2}\right)^{\alpha_{3}}}{\left(V e(x, t)+\alpha_{4}\right)^{\alpha_{5}}} d A d t\right) .
\end{aligned}
$$

[37] After subtracting the contribution due to fire effects, the small debris basins still display significant scatter around an average value of $0.9 \mathrm{~mm} \mathrm{yr}^{-1}$ (Figure 8). Nonetheless, the average value for small watersheds is now more consistent (only 25\% higher) with denudation values recorded in dams. Because some debris basins have not been burned during their operative history, we can evaluate our fire correction procedure. Two thirds of these debris basins yield erosion rates less than the average value of $0.9 \mathrm{~mm} \mathrm{yr}^{-1}$ (Figure 8). More restrictively, if we consider only unburned catchments, debris production is $\leq 0.3 \mathrm{~mm} \mathrm{yr}^{-1}$. This could suggest that our procedure has overestimated the nonfire production rates. The watersheds of these more slowly eroding basins, however, have less steep hillslopes than the regional average. Perhaps more importantly, they all were built after the major, debrisproducing storm of 1969 (Figure 7) such that their debris production may not be representative of longer-term rates. More generally, given the data scatter, a possible bias in the fire correction procedure can not be quantitatively assessed.

[38] For the whole history of each debris basin the fire contribution can be expressed as the difference between observed $\left(Q_{S}\right)$ and estimated nonfire $\left(Q_{B}\right)$ production, $Q_{F}=$ $Q_{S}-Q_{B}$. This fire contribution may reach up to $80 \%$ of the recorded sediment production (Table 1), especially for small basins burned multiple times, e.g., the Auburn debris basin.

[39] In order to compare fire contributions between the different watersheds, we normalize by the number of fires $n_{F}$ (the more fires a basin sustained, the greater its fire sediment contribution) and by the background denudation rate, which we approximate by the nonfire production, $Q_{B}$, value divided by the recording duration, $\Delta t$. This normalized contribution due to a unit fire $\left(\Phi_{F}\right)$,

$$
\Phi_{F}=\frac{Q_{S}-Q_{B}}{n_{F} Q_{B}} \Delta t,
$$




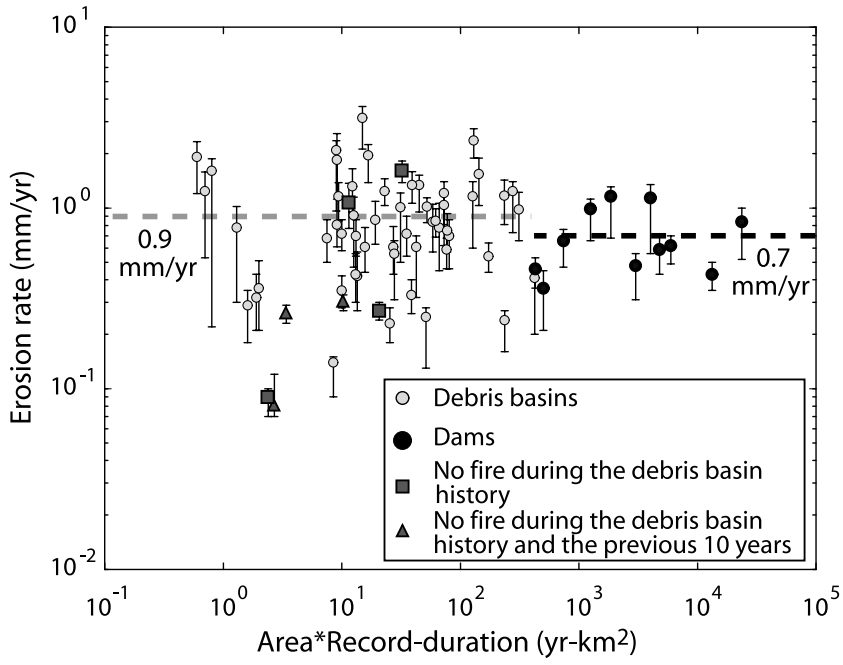

Figure 8. Computed erosion rates $\left(\mathrm{mm} \mathrm{yr}^{-1}\right)$ for debris basins (gray circles) and dams (black circles) after subtraction of the contribution due to fire effects. After correction, data scatter for the debris basins has been reduced but remains significant. The average value for small watersheds, however, is now only $25 \%$ more than denudation values recorded in dams.

is expressed as an equivalent duration of nonfire (or background) sediment production.

[40] This value commonly ranges between 10 and 70 years of sediment production (Table 1 and Figure 9) and is negatively correlated with basin size. As noted qualitatively from the debris production history of the Auburn debris basin and the San Gabriel dam (Figure 8), the fire contribution to the sediment production appears to be lower for larger watersheds than for smaller ones. The drainage area versus unit-fire-contribution data (Figure 9) can be interpreted to display two domains with a threshold of $\sim 1_{-0.5}^{+2} \mathrm{~km}^{2}$, although a fit by a step-like relation is statistically little better than a fit by a power law of exponent -0.1 (applying a bootstrap analysis to the logscale values yields rms errors of $0.275 \pm 0.03$ and $0.29 \pm 0.03$, respectively). The larger basins are clearly less affected by fire yet display a more uniform fire influence. Excluding some hidden bias introduced by slope distributions (average slopes do not show such an area dependency), there are few reasons to ascribe different erosional responses to hillslopes of small and large watersheds. Instead, we speculate that the diminishing impact of fires reflects the way sediment moves through these catchments. During severe storms, flood discharges can carry all the sediment supplied from the hillslopes. In contrast, following a fire, minor storms commonly are able to generate small debris flows that transport sediments coming off the hillslopes and mobilize debris already in the valley bottoms but are commonly incapable of transporting this debris at long distances. This is particularly true when a fire has burned only part of the watershed. In contrast with burned areas where a fireinduced hydrophobic soil layer [Krammes and Debano, 1965] enhances runoff, unburned areas produce little runoff and favor a drop in the sediment transport capacity of the higher-order channels.
[41] In large watersheds during minor storms, small debris flows within burned areas could convey available sediments to first-order and second-order channels, where they would be temporarily stored. Only large-scale floods following major storms would be likely to remobilize and flush these sediments through the higher-order channels. Consequently, sediment production peaks in large catchments would be expected to lose a close correlation with fire history (Figure 7), whereas catchments commonly encompassing $1-2 \mathrm{~km}^{2}$ are more likely to be entirely burned and to provide higher short-term sediment yields (Figure 9). Accounting for such inertial behavior in large catchments would lower the nonfire sediment production as recorded in dammed catchments by $10-15 \%$ if we consider the average unit fire contribution of 30 years for catchments smaller than $1 \mathrm{~km}^{2}$ (Figure 9).

\subsection{Natural Fires and Long-Term Erosion Rates}

[42] Although human activities have clearly increased fire frequency, particularly along the southern front of the San Gabriel Mountains, fires also have natural causes (ignition by lightning) and thus must be considered as an integral part of the long-term erosional process. Although derivation of an exact estimate of late Holocene erosion rates is impractical, we can assess the anthropogenic enhancement of "natural" erosion rates and thereby create an erosional framework for studying hillslope processes where debris production occurs. To assess the role of natural fire in

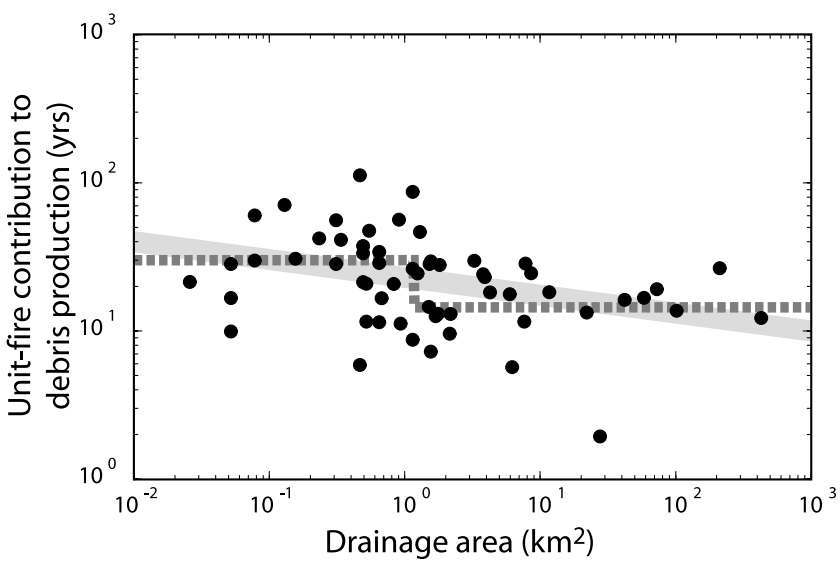

Figure 9. Fire signature in sediment production as a function of the debris basin drainage area. The fire signature is expressed as the sediment produced as a consequence of a unit fire affecting the whole watershed, in terms of equivalent number of years of denudation without fire. This signature decreases slightly with watershed area and suggests, as qualitatively discussed in Figure 7, that large watersheds respond differently than do small ones to external forcing like storms and fires. Whereas a step-like relationship (thick dashed line) is statistically little better than a power law of exponent -0.1 (thick solid line), a transition seems to occur at watershed sizes of $\sim 1_{-0.5}^{+2} \mathrm{~km}^{2}$ and may correspond to the transition between transport mostly by debris flows versus fluvial transport. For large watersheds, only major floods would thus be able to effectively convey previously eroded material (during storms or after a fire) to the dams. 
erosion rate calculations, we first note that the Transverse Ranges represent climatic and vegetation conditions intermediate to those prevailing in Baja California and Oregon, where long-term fire ignition rates have been reconstructed. When compared to the entire United States from 19891996, these three regions, and more generally the west coast states, are characterized by a low annual density of cloud-toground lightning, but among the three regions, the annual flash rates are similar (i.e., the number of lightning bolts per hour of electrical thunderstorm) [Huffines and Orville, 1999]. We therefore assume that given similar flash rates, local climatic aridity has a primary role in fire ignition and propagation in the west coast states and that the return period for natural burning in the San Gabriel is intermediate between Oregon and Baja California: on the order of $T_{n f}=$ $200 \pm 100$ years. To estimate the average contribution of natural fires, one might run a Monte Carlo procedure to explore the impact of fire frequency in conjunction with intense rain. Given the large uncertainties in the relationship between sediment production, vegetation cover, and topography (equations (2) and (3)), however, we bypassed this computation and simply assumed that the extra denudation rate produced by the fires during the twentieth century can be approximated by the nonfire production rate multiplied by the unit fire contribution and the natural fire frequency:

$$
\frac{Q_{B}}{A \Delta t} \frac{\Phi_{F}}{T_{n f}}\left(=\frac{Q_{S}-Q_{B}}{A n_{F} T_{n f}}\right)
$$

The resultant "natural" erosion rates for debris basins and dams (Table 1) indicate that, on average, natural fire ignition accounts for $10 \%$ of the total denudation (this low value is partly attributable to the damping effect of storage of fire-related sediment in large watersheds).

\section{Hillslope Sediment Production on the Hillslopes of the San Gabriel Mountains}

4.1. Photogrametric Analysis of the Recent Landslides: Area Distribution of Landslides

[43] In active mountain areas, like the Southern Alps [Hovius et al., 1997] or the Himalayas [Burbank et al., 1996], landsliding represents the major erosional process on hillslopes. Despite its importance in these settings, the erosional contribution and role of landsliding in the Transverse Ranges, where denudation rates are 5-10 times lower, are poorly known. We therefore conducted a systematic mapping of landslides according to the procedures defined by Hovius et al. [1997] or Ohmori and Hirano [1988].

[44] We analyzed four generations of photos to assess the temporal and spatial distribution of landslides. Given the location of the debris basins on the southern flank of the mountains, we focused the landslide mapping on the same area (Figure 4a). Two series of air photos (1928, scale $1: 18,000 ; 1952 / 1954$, scale $1: 20,000)$ provide complete coverage of the study region. Two series (1938/1939, scale $1: 20,000 ; 1973$, scale 1:32,000) are incomplete: the first because it is confined primarily to San Bernardino County and concerns only the eastern part of the study area and the second because of extensive cloud cover. Only the southcentral region has been inspected with at least three different

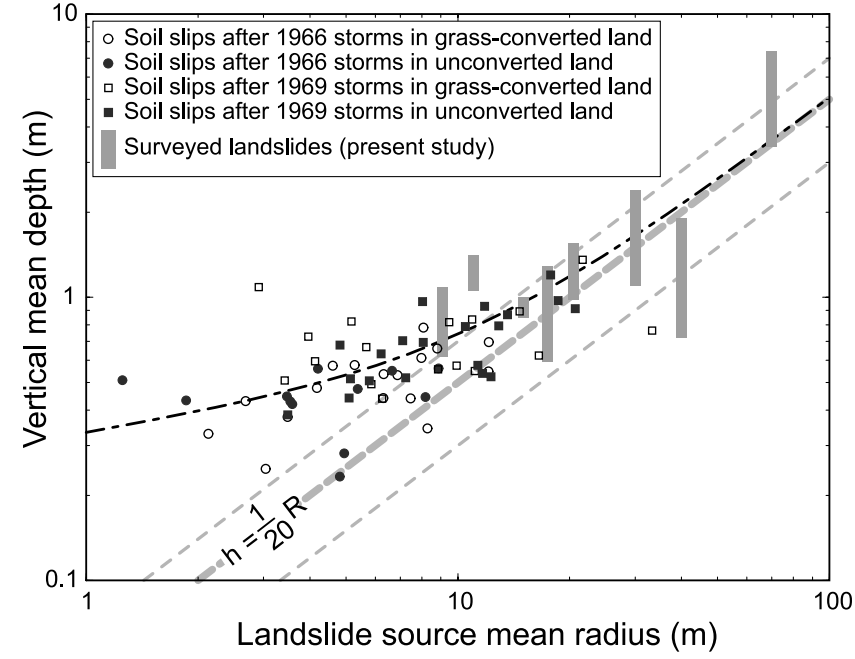

Figure 10. Average thickness of eight bedrock-landslide scars surveyed by a laser ranger in the San Gabriel Mountains. The measurements are consistent with a previously proposed relationship $h=(0.05 \pm 0.02) R$ [Ohmori, 1992], with $h$ being vertical thickness and $R$ being the mean radius of the landslide scar (dashed lines show the relationship and its uncertainties). On the basis of data (circles and squares) from Rice et al. [1969] and Rice and Foggin [1971], the $\sim 20: 1 R / h$ ratio is not valid for the smallest shallow landslides (average trend shown by the dash-dotted line), irrespective of vegetation cover, probably because the soil-bedrock interface represents a preferential discontinuity for slip that is independent of landslide size.

photo sets. On these air photos, recent landslides were distinguished by their higher surface reflectivity and, for the larger slides, by morphometric criteria. In many sparsely vegetated areas, however, landslide scars can hardly be discriminated within rocky talus slopes.

[45] All landslide scars identified on the air photos were redrawn on a set of 1:20,000 orthophotos and were later digitized into a GIS. The uncertainty on the exact location of these scars is on average of $1-2 \mathrm{~mm}$ on the orthophotos, whereas the error on the width of the smallest landslides is of the order of $0.5 \mathrm{~mm}(\sim 10 \mathrm{~m}$ on the ground). On the larger-scale photos we were able to map most shallow landslides larger than $10 \mathrm{~m}$.

[46] Following the previously outlined method [Hovius et al., 1997], we digitized the landslides for each of the four aerial photo sets. The surface area and number of digitized landslides are $177 \mathrm{~km}^{2}$ and $60,100 \mathrm{~km}^{2}$ and $267,1265 \mathrm{~km}^{2}$ and 815 , and $495 \mathrm{~km}^{2}$ and 219 for the 1928, 1938, 1954, and 1973 aerial photos, respectively.

[47] In order to help convert mapped landslide extent to landslide volume, we conducted field surveys of eight different landslide scars with a laser range finder. As previously observed by Ohmori [1992] in Japan, and if we exclude the smallest slides (Figure 10), the landslides' mean vertical depths roughly follow a simple linear relation relative to the average size of the scar:

$$
H=\varepsilon D,
$$


where $\varepsilon=0.05 \pm 0.02$ and $D$ (the square root of the area) serves as a proxy for the characteristic linear dimension of a scar.

[48] To determine erosion rate, it is also necessary to assess the temporal resolution, i.e., the average time for revegetation of the landslide scars. Following Hovius et al. [1997], we initially assume a single and conservative value of 15 years: The validity of such assumption will be discussed in section 4.2. The average erosion rate by twentieth-century landsliding was thus estimated to be $\sim 0.08 \mathrm{~mm} \mathrm{yr}^{-1}$ across the mapped area in the San Gabriel Mountains. Striking spatial contrasts are observed with higher rates in the Cucamonga and Central Sierra Madre blocks and the lowest rate in the western San Gabriel (Figure 11 and Table 2).

\subsection{Long-Term Denudation Rate by Landsliding, Uncertainties on Fresh Scar Survival, Vegetation Regrowth, and Maximum Size of Landslide}

[49] Although the range of landslide sizes is more restricted in the San Gabriel Mountains than in the Southern Alps, the landslide distribution in each area appears also to follow a power law distribution (Figure 11) for landslide scars larger than the mapping resolution limit of $100-500 \mathrm{~m}^{2}$ :

$$
F\left(A>A_{0}\right)=\kappa A^{-\beta},
$$

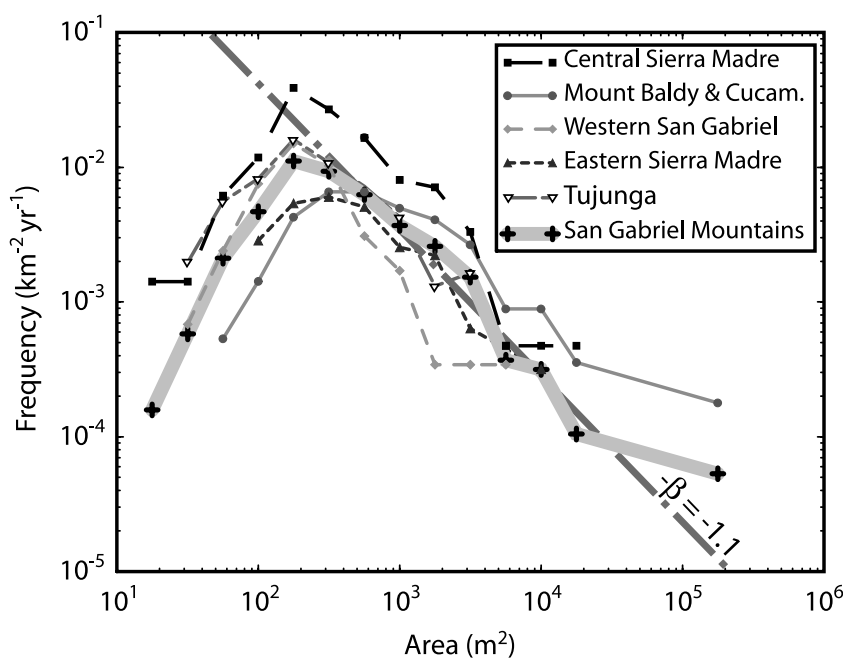

Figure 11. Landslide size-frequency distribution (thick gray line) for landslides mapped on four generations of aerial photos (see Figure 4a for the mapping zones). The frequency curve (thick gray line) displays power law scaling behavior with a cutoff between $2 \times 10^{2}$ and $8 \times 10^{2} \mathrm{~m}^{2}$, mostly or partly due to mapping resolution. For landslides $>8 \times 10^{2} \mathrm{~m}^{2}$ (and excluding the largest and single poorly resolved event), a slope exponent $-\beta=-1.1 \pm 0.15$ has been estimated (dash-dotted line) by linear regression. For the five different physiographic units of the San Gabriel Mountains, the size-frequency distributions have also been derived from the landslides mapped on the 1952-1954 aerial photo set. For these five morphotectonic regions and for landslide areas $>300 \mathrm{~m}^{2}$, despite fewer data for building histograms, the curves are still roughly parallel to the slope exponent $-\beta=-1.1$, but their intercepts define different denudation rates by landsliding.
Table 2. Regional Average of Sediment Production Rate by Landslides Digitized From the 1952-1954 Aerial Photo Set ${ }^{\mathrm{a}}$

\begin{tabular}{lcc}
\hline \multicolumn{1}{c}{ Block } & $\begin{array}{c}\text { Hillslope } \\
\text { Denudation } \\
\text { by Present } \\
\text { Landslides }\end{array}$ & $\begin{array}{c}\text { Long-Term } \\
\text { Denudation } \\
\text { by Major } \\
\text { Landslides }\end{array}$ \\
\hline Mount Baldy and Cucamonga block & $0.20 \pm 0.080$ & $0.55 \pm 0.25$ \\
Central Sierra Madre block & $0.14 \pm 0.056$ & $0.54 \pm 0.26$ \\
Eastern Sierra Madre block & $0.04 \pm 0.016$ & $0.25 \pm 0.09$ \\
Tujunga block & $0.04 \pm 0.016$ & $0.27 \pm 0.13$ \\
Western San Gabriel block & $0.02 \pm 0.008$ & $0.10 \pm 0.04$ \\
San Gabriel Mountains & $0.08 \pm 0.032$ & $0.28 \pm 0.15$ \\
\hline
\end{tabular}

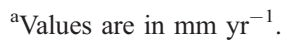

with $F$ being the cumulative distribution and $\beta=1.1 \pm 0.15$ the slope exponent obtained by fitting (linear regression) the size-frequency distribution in the range of better resolution between $5 \times 10^{2}$ and $2 \times 10^{4} \mathrm{~m}^{2}$.

[50] Here the slope exponent $\beta$ is close to that observed in New Zealand ( $\beta=1.1)$ [Hovius et al., 1997] and suggests that small landslides are proportionally more frequent in the San Gabriel. However, as noted by Ohmori and Hirano [1988] and Hovius et al. [1997], as long as the scaling exponent $\beta$ is lower than 1.5 , the denudation by landsliding is volumetrically dominated by the largest landslides. Similar to seismic hazard estimates, it is important to correctly estimate the largest likely event in order to derive the longterm production rate of sediments. In the San Gabriel Mountains the maximum size of the mapped landslides that occurred between 1928 and 1973 is only $2 \times 10^{-1} \mathrm{~km}^{2}$. However, if we consider all topographically expressed landslides, much larger landslides have been described [Morton et al., 1989]. The most prominent landslide deposit ( $\sim 1 \mathrm{~km}^{2}$ source area) can be observed in the North Fork of the San Gabriel River ("Crystal Lake landslide," outlined polygon in Figure 4a). In the San Gabriel Mountains, according to relationship (9), the return period for a $1 \mathrm{~km}^{2}$ landslide would be $\sim 700$ years across the whole study area. Although such large slides would be unexpected with the 50 year time window of our study, such rare and large events exert a significant influence on the long-term denudation rate by landsliding. Assuming that the scaling law (9) remains valid even for the largest landslides, as observed in New Zealand, the long-term denudation can be approximated by

$$
\dot{e}_{L} \approx \frac{2 \beta \varepsilon \kappa}{(3-2 \beta)} A_{\max }^{\frac{3}{2}-\beta}
$$

[Hovius et al., 1997], with $A_{\max } \cong 1 \mathrm{~km}^{2}$.

[51] At the scale of the San Gabriel Mountains, by including the contribution of large landslides, the landslide denudation rate rises from 0.08 to $0.28 \mathrm{~mm} \mathrm{yr}^{-1}$ (Table 2). For the different morphotectonic blocks the long-term denudation rate by landsliding ranges between $0.1 \mathrm{~mm} \mathrm{yr}^{-1}$ in the Western San Gabriel block and $0.5 \mathrm{~mm} \mathrm{yr}^{-1}$ in Cucamonga and central Sierra Madre blocks (Table 2 and Figure 11).

[52] There are, however, large uncertainties in these values because they depend on a correct estimate of both $A_{\text {max }}$ and the slope exponent. In particular, it is not possible to assess whether the magnitude-frequency distribution 
keeps the same slope or has a steeper one for these major events. This slope exponent is also biased by our counting method because the revegetation time of landslide scars has been assumed constant.

[53] In order to evaluate this assumption, we investigate the temporal preservation of landslide scars as a function of their area. It is not surprising that given the Mediterraneantype climate, scars are slowly revegetated and may be identified as "fresh" by our visual counting criteria for many years after the failure. It is also possible that scars remain active with small rockfalls in the years following an initial failure. By superposing and comparing our landslide maps representing four snapshots spanning 45 years, we can assess the persistence of landslide scars over different time intervals (Figure 12). This comparison shows that persistence is clearly dependent on the size of the source area: small landslides $\left(A<1000 \mathrm{~m}^{2}\right)$ are quickly revegetated (Figure 12). In contrast, larger scars persist $>25$ years, as expected for slowly revegetating scars in which soil has been totally removed and colluvial deposits are restricted to the periphery. This time-area dependency may be approximated by a sigmoid curve. Because we lack a more quantitative basis to define the temporal aspects of vegetative regrowth, fine tuning of equation (10) using a more precise time dependency is presently unwarranted.

[54] Delayed revegetation and its time-area dependency lead both to an underestimation of the contribution of small slides with recovery times $<15$ years and to an overestimation of the frequency of occurrence of large slides. We partially compensate for this latter bias by counting only the newly created landslides, i.e., the ones having been generated since the last suite of photos. Unfortunately, for more than $50 \%$ of the San Gabriel Mountains we have only the 1952-1954 aerial photo set such that subtraction of successive sets was not possible. As a consequence of these two biases, the slope exponent is commonly underestimated, and the landslide contribution to erosion may therefore be overestimated. Finally, introducing "Double Pareto" statistics [Stark and Hovius, 2001] to our analysis would also lead to an increased $\beta$ value and might alter the overall conclusion that large landslides dominate sediment production. Given these uncertainties, we suggest that our relative rates of landslide erosion are reliable between different tectonomorphic units (Figure 11) but that the absolute rates may be as much as $30-50 \%$ too high.

\subsection{Climatic Versus Seismic Triggered Landslides}

[55] Seismic shaking has long been recognized as a major factor for triggering landslides. In Papua New Guinea, unusually large landslides following a $M_{w}=6.9$ earthquake [Densmore and Hovius, 2000] were volumetrically equivalent to 350 years of "normal" landsliding. In California the Northridge earthquake $(M=6.7)$ triggered more than $10^{4}$ landslides and rockfalls [Harp and Jibson, 1996]. In seismically active regions, such as the Transverse Ranges, it is tempting to suppose that a significant fraction of landslides, perhaps even the majority, are triggered by earthquakes. Such a scenario could explain the apparent difference between sediment production by landsliding in the San Gabriel and debris basin production during the last 50 years. To assess the impact of seismically triggered landslides, we begin by assuming that during an earthquake

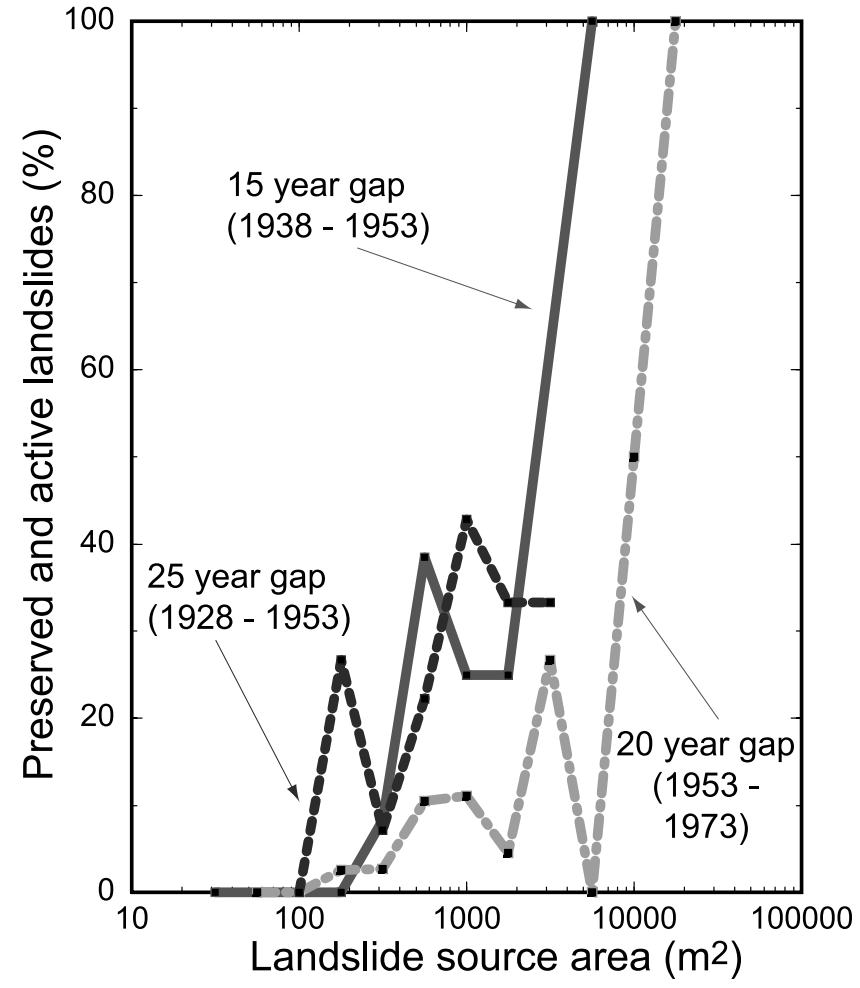

Figure 12. Percentage of landslides that survive as recognizable features on aerial photos over intervals of 15-25 years, plotted as a function of landslide area. For all intervals ( $=25$ years) considered in this study the same large landslides have been repeatedly recognized and mapped on two generations of aerial photographs. This duplication results most probably from a relatively slow revegetation rate of large landslides. By contrast, small and shallow landslides are more rapidly revegetated. The 1953-1973 curve is unexpectedly shifted (toward larger areas) relative to the others, despite a similar time window. This shift may be ascribed to the lower resolution of the 1973 aerial photos such that fewer small landslides can be recognized compared to the 1952-1954 photo set.

the size of the area affected by landslides and the volume of sediment produced by them are related to earthquake magnitude, M, by a power law [Keefer and Wilson, 1989]:

$$
\log A_{M}=M-3.46
$$

and

$$
\log V_{M}=\lambda M+\gamma,
$$

where $A_{M}$ represents the area affected by landslides (in $\mathrm{km}^{2}$ ), $V_{M}$ is the total volume (in $\mathrm{m}^{3}$ ) of landslides triggered by an earthquake, $\lambda=1.44 \pm 0.2$, and $\gamma=-2.34 \pm 1.5$. In fact, the number and volume of landslides triggered by seismic shaking depend also strongly on slope stability, in particular on hillslope steepness [Schmidt and Montgomery, 1995], such that any landslide rule would need to be calibrated in each different morphotectonic setting. In the following analysis we assume that the slope exponent $\lambda$ in 
equation (12) has been approximately captured by Keefer and Wilson's [1989] global approach. By contrast, we suspect that the exponent value $\gamma$ depends highly on the morphotectonic setting and hillslope morphology in the affected area.

[56] For the San Gabriel Mountains we roughly calibrated the exponent $\gamma,-3.7<\gamma<-3.2$, by considering the volume of debris $\left(\sim 2-5 \times 10^{6} \mathrm{~m}^{3}\right)$ produced by landslides during the $M=6.5$ San Fernando 1971 earthquake [Morton, 1975] (see detail in section 20). The area in which seismically triggered landslides were mapped is roughly $250 \mathrm{~km}^{2}$ (Figure $4 \mathrm{a}$ ) such that the debris production represents an equivalent erosion of $\sim 12 \mathrm{~mm}$.

[57] At a given point $\mathbf{x}$ of the landscape, erosion rate, $\dot{e}_{S S}(\mathbf{x})$, by seismic landslides can be computed by convolving the volume-magnitude relation (12) with the GutenbergRichter law:

$$
\dot{e}_{s s}(\mathbf{x})=\iint_{\Sigma_{X}} v_{M} v_{(M, \overline{(X-x)})} n_{(M, X)} d \mathbf{X} d M,
$$

where $\Sigma_{\mathbf{x}}$ is the seismically affected area that is also capable of producing landslides within the area of interest, $v_{(M, \overline{(X-x)})}$ is the volume of sediments per unit area produced by an earthquake of magnitude $M$ at a distance $(\overline{X-x})$ from its epicenter in $\mathbf{X}$, and $n_{(M, X)}$ is the frequency of occurrence of a magnitude $M$ earthquake linked to the Gutenberg-Richter distribution by

$$
n=-\partial N / \partial M \text { and } \log N\left(M>M_{0}\right)=-b M_{0}+a .
$$

[58] As a first approximation and because we only seek a rough estimate of seismic effects, we consider a homogeneous distribution of seismic events around the studied San Gabriel region encompassing an area greater than the zone of influence of the largest earthquake. Relation (13) can thus be simplified:

$$
\dot{e}_{S S}=\int_{M} V_{(M)} n_{(M)} d M
$$

Commonly, the $b$ value is around unity. In that case, or as long as $b<\lambda$, the second term after integration can be neglected:

$$
\dot{e}_{s S} \cong \frac{b}{(\lambda-b)} 10^{(\lambda-b) M_{\max }+(\gamma+a)},
$$

where $a$ corresponds to a constant calculated for a cumulative frequency $N$ expressed as units of time and area. On the basis of data from the USGS historical earthquake catalog (1769-1974) and more recent monitored instrumental seismic activity (since 1973) http://neic.usgs.gov/ neis/epic/epic.html), we analyzed the Gutenberg-Richter distribution for the Transverse Ranges: $M_{\max }$ is estimated to be $M=8, b=1$, and $a=0.8$ (for $N$ expressed in number of events per year and per $\mathrm{km}^{2}$ ). Combining this observed seismicity with equation (16) yields estimates for seismically induced erosion rates in a given region. For example, in the Tujunga block (Figure 1) the seismic contribution to erosion is predicted to be $0.01-0.03 \mathrm{~mm} \mathrm{yr}^{-1}$, i.e., less than $10 \%$ of the long-term production by climatically induced landslides. It could be argued that the recording period for historical and instrumental seismicity is insufficient in view of fault behavior. Assuming that $b=1$, we thus computed the parameter $a$ according to the number and recurrence interval of the potential moderate $\left(6.5 \leq M_{w} \leq 6.8\right)$ earthquakes in the Los Angeles metropolitan region [Dolan et al., 1995]. The corresponding probability of having nine moderate earthquakes per century is indeed considerably higher than the number of $M_{w} \approx 6.7$ earthquakes during the past century and leads to a higher value for $a \approx 1.4$. With such a seismicity rate, the potential sediment contribution of the coseismic landslides could increase by a factor of 4 but still would represent a minor contribution to the sediment budget. Locally, in particular close to the San Andreas fault where probability of peak ground acceleration is higher by a factor $>2$ than in the rest of the San Gabriel Mountains (California Geological Survey; http://www.consrv.ca.gov/cgs/rghm/psha/pga.htm), this rate may be significantly underestimated by our approach. However, this region is not directly under the scope of the present study and does not intersect with the watershed areas contributing to sediment production in the debris basins and dams. Therefore if our crude approximation is valid, seismically triggered landslides would not be major contributors to the total denudation by landslides within most of the crystalline regions of the San Gabriel Mountains. In contrast, the landslide volume in the Tertiary sediments of the Transverse Ranges may have been much greater following the Northridge earthquake [Harp and Jibson, 1996]. However, a more systematic study would be necessary to constrain the potential role of lithology in influencing the ratio of climatic versus seismically triggered landslides.

\subsection{Denudation by Soil Slippage and Shallow Landslides}

[59] In contrast to deep-seated landslides, shallow landslides and soil slippage are commonly too small to be mapped in most aerial photos, and rapid revegetation causes them to be underrepresented in successive aerial imagery. According to (10), if shallow landslides followed the same scaling relation (9) as deep-seated landslides, their contribution to the total debris volume would be negligible. We suggest, however, that shallow landslides do not conform to the same "rules" as deep-seated slides. For example, many small slides are thicker (Figure 10) than would be predicted by the area-depth relationship (equation (8)) for larger, bedrockinvolved slides. For shallow landslides the position of the bedrock-regolith interface is probably a better predictor of the failure plane than is the area of the slide. Rice et al. [1969] and Rice and Foggin [1971] studied the shallow landslides that occurred in the San Dimas Experimental Forest during severe storms in 1965-1966, 1966-1967, and 1969. Their study primarily focused on Bells and Monroe Canyons in the Big Dalton watershed (Figure 4c), where they mapped shallow slides. Their key conclusions were that soil failures are slope-dependent and inversely related to the size and density of vegetation but unrelated to underlying bedrock lithology (schist, gneiss, diorite, or dacite). Assuming a soil and colluvium density of $\sim 1250 \mathrm{~kg} \mathrm{~m}^{-3}$ [e.g., Reneau and 
Dietrich, 1991], mean erosion by shallow landsliding in the brush-covered areas of the Big Dalton watershed was equivalent to $\sim 1.0 \mathrm{~mm}, 0.2 \mathrm{~mm}$, and $14 \mathrm{~mm}$ during 1965-1966, 1966-1967, and 1968-1969, respectively, whereas basin-wide shallow landslide contributions (including contribution of grass-converted areas) averaged $2.2 \mathrm{~mm}$, $0.4 \mathrm{~mm}$, and $19 \mathrm{~mm}$ for these intervals (Figure 13). Conversion from brush to grass in the upper Big Dalton watershed led to a threefold (in 1968-1969) and sevenfold (in 1965-1966) increase in sediment production during intense winter storms. Although the shallow landsliding data (symbols) for the 1968-1969 storms approximately match the sediment production recorded at Big Dalton dam (solid bars, Figure 13a), shallow landsliding can account for only about one fourth of the total sediment during the 1965-1966 and 1966-1967 storms. Although potentially due to the somewhat steeper and hence more landslideprone slopes in the part of Big Dalton watershed that lies downstream of the San Dimas study area, the discrepancy is more likely to result from reworking of sediment accumulated in fluvial channels since the watershed burned in 1960. The 1965-1966 storms are indeed the first major storms since that fire. If this interpretation is correct, it clearly illustrates our proposed temporal deconnection between hillslope erosion and sediment transport in fluvial network: Large storms not only generate sediments from landslides, but they mobilize sediments stored in channels, thereby amplifying the total sediment production.
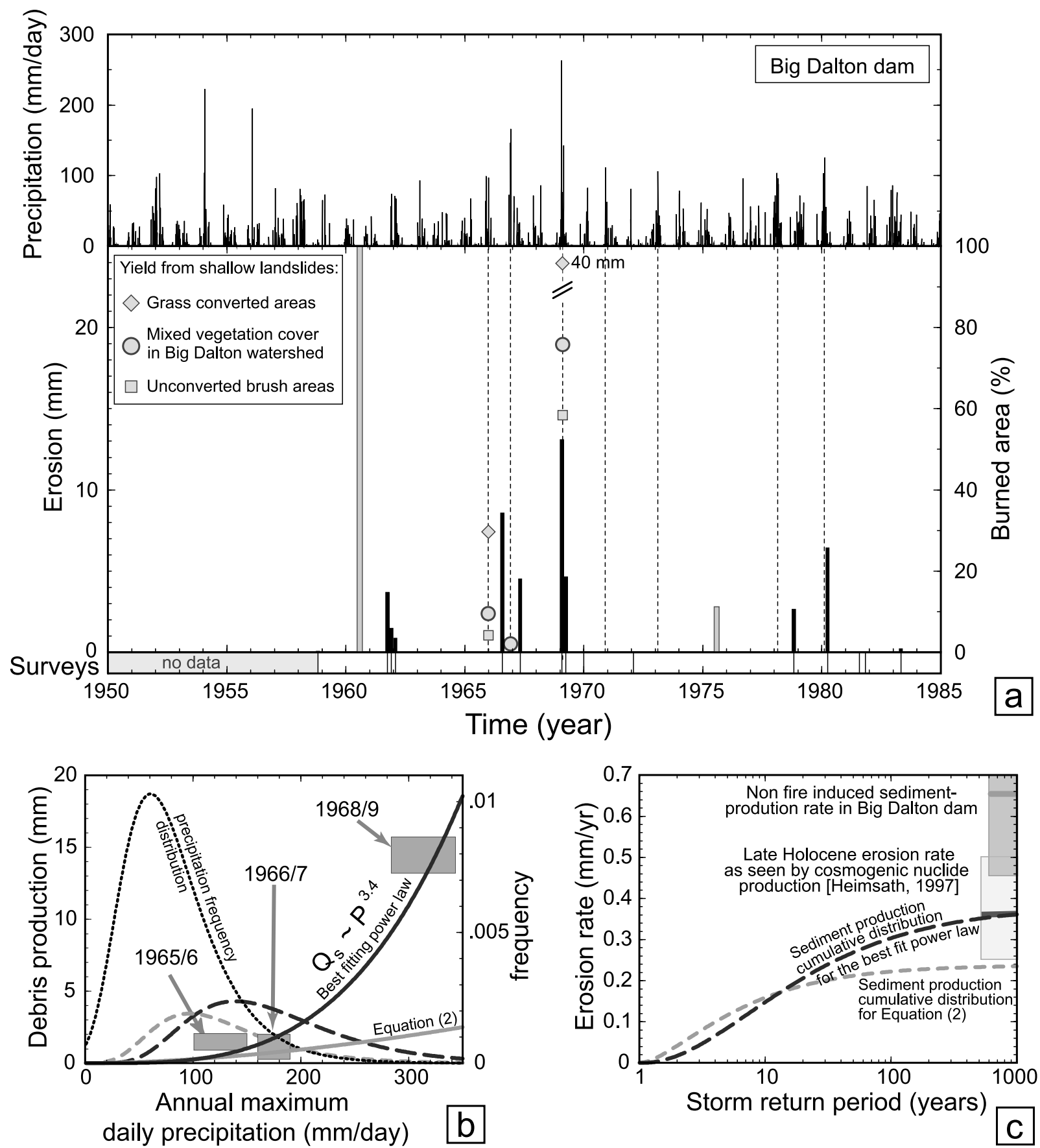
[60] On the basis of the rain gauge record, the 19651966, 1966-1967, and 1969 storms correspond to $\sim 5$ year, 12 year, and $>50$ year return periods for the maximum 24 hour precipitation. If we consider the erosion by shallow landslides during these intervals versus the concurrent maximum daily precipitation, these data can be fit with a power law (Figure 13b) with an exponent of 3.4: a value two times higher than the exponent deduced from relation (3) after inversion of the entire debris basin data set. The convolution of this erosion function with the maximum 24 hour precipitation frequency distribution (Figure 13b) predicts a sediment production frequency distribution (Figure 13b) and a cumulative distribution of erosion (Figure 13c). The asymptotic value of the cumulative frequency corresponds to the long-term average erosion rate, i.e., a value of $0.4 \mathrm{~mm} \mathrm{yr}^{-1}$ for erosion by shallow landslides (Figure 13c). This contribution is twice as large as the contribution of deep-seated landslides and appears to be of the same order as the nonfire sediment production at Big Dalton or San Dimas dams (Table 1).

[61] Analysis of the aerial photos suggests that twentiethcentury denudation by deep-seated landslides has been an order of magnitude lower than sediment production in the debris basins, even after subtracting the effect of increased fire frequency. In contrast, if Rice and Foggin's [1971] observations in the San Dimas Experimental Forest can be extended across the San Gabriel Mountains, shallow landslides and soil slippage could represent half of the total sediment production; the remainder would most likely correspond to superficial erosion, such as dry and wet ravel, after a fire.

[62] In the long term, i.e., before anthropogenic disturbance, surface and shallow erosion processes are likely to have remained dominant relative to deep-seated landslides (at least twice as large). However, our landslide analysis still encompasses too many uncertainties, including the slope exponent $\beta$, rates of revegetation, effects of earthquake triggering, and the validity of the scaling law (9) up to the size of the maximum slides, to provide a definitive test of relative long-term rates.

[63] If, in the long term, shallow landslides contribute strongly to debris production as observed during the twentieth century, it requires equivalent soil production rates.
Before assessing this possibility, we must, however, first determine whether the denudation pattern is roughly at steady state in the San Gabriel Mountains. One way to assess a potential topographic steady state is to verify the necessary condition that river network and landscape overall are eroding at the same rate.

\section{River Incision and Morphometric Analysis in the Transverse Ranges}

\subsection{Fluvial Incision}

[64] Despite the presence of fluvial terraces in the San Gabriel Mountains [Bull, 1991], most of these are aggradational terraces such that their dissection reveals little about bedrock incision rates. Consequently, we have adopted a more regional approach by defining a proxy for fluvial incision. The geometry of a river channel expresses river adjustment to various external forcing factors (climate, lithology, tectonics) and the sediment supply from the surrounding hillslopes. Among other factors, the river gradient is probably most representative of the ability of a river to transport sediments and erode bedrock. Variations of river gradients may thus be used to detect zones of active uplift [Seeber and Gornitz, 1983; Keller, 1986; Lavé and Avouac, 2001]. Hereafter, we use river gradient and catchment characteristics to try to derive more quantitative erosion estimates from the geometry of the fluvial network draining the San Gabriel Mountains.

[65] Although bedrock incision likely results from complex physical processes and interactions [e.g., Sklar and Dietrich, 1998; Hancock et al., 1998; Howard et al., 1994; Foley, 1980a, 1980b], simple rationales underpin a macroscopic relationship that relates river channel properties to the rate of fluvial incision, into the bedrock. According to Howard et al. [1994], this relationship could reduce to a stream power law which depends on the drainage area, $A$, and the local river gradient, $S$ :

$$
\dot{i}=K A^{m} S^{n} \text {. }
$$

[66] Among other semiphysical laws, this relation encompasses stream power, which relates incision to the product

Figure 13. (a) Comparison between (top) precipitation, fire history (open rectangles), sediment production in the Big Dalton catchment (solid lines), and debris production by shallow landslides under different vegetation cover in Bell Canyon (see location in Figure 4c) as mapped by Rice et al. [1969] after the 1965-1966 and 1966-1967 storm seasons and by Rice and Foggin [1971] for the 1968-1969 storm season. If sedimentation in Big Dalton dam after the 1968-1969 storm represents erosion by shallow landslides, it is four times higher than for the 1965-1966 and 1966-1967 storms. This misfit could result from a reworking of sediment stored in the fluvial network after the watershed burned in 1960 . Note that significant sediment production requires large storms preceded by extensive fires. (b) Sediment production as a function of the annual maximum daily precipitation according to (1) relation (2) (light gray line) and (2) a power function (dark gray line with exponent $=3.4$ ) that roughly fits the calibrated debris production by shallow landslides for the three storm seasons. When convolved with the frequency distribution of the annual maximum daily precipitation (thin black dashed line $=$ Gumbel fit of the 50 year precipitation record), these yield sediment-production frequency distributions (thick dashed lines). (c) Corresponding cumulative sediment-production frequency distribution as a function of the storm return

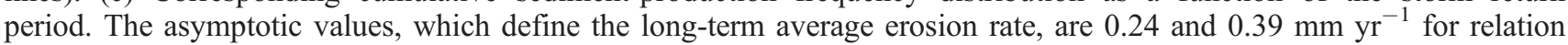
(2) and debris production by shallow landslides, respectively. The first value largely underestimates the complete production because it is based on annual maximum precipitation rather than on daily precipitation (which would yield a rate of $0.9 \mathrm{~mm} \mathrm{yr}^{-1}$ ). The second value matches erosion rates and soil production rates derived from cosmogenic nuclide analysis [Heimsath, 1999] but is clearly lower than the fire-corrected sedimentation rate in Big Dalton dam. 


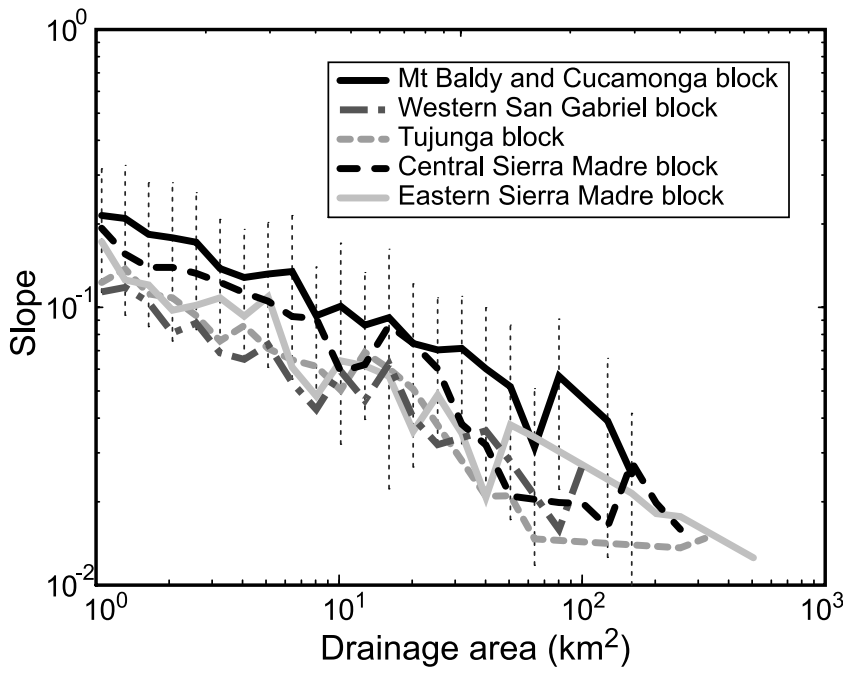

Figure 14. Slope-area relationship for the San Gabriel Mountains. For drainage areas $>1 \mathrm{~km}^{2}$, the average curvature $(-m / n)$ ratios range between -0.37 and -0.43 for the five morphotectonic regions, as expected from a shear stress or unit stream power model for fluvial incision. Vertical dashed lines represent the $1-\sigma$ uncertainties on the Mount Baldy-Cucamonga region mean slopes.

of the slope and discharge ( $m=0.7-1.0$ and $n=1)$, unit stream power $(m=0.35-0.55$ and $n=1)$, and fluvial shear stress $(m=0.25-0.35$ and $n=0.7)$ [Lavé and Avouac, 2001; Slingerland et al., 1998]. So far, field investigations and calibration are still too scarce and contradictory to discriminate among the proposed models [Stock and Montgomery, 1999]. Despite failing to account for the impact of sediment supply on a river's abrasion capacity [e.g., Sheperd, 1972; Sheperd and Schumm, 1974; Foley, 1980a, 1980b; Sklar and Dietrich, 1998], recent studies using a shear stress model appear to provide first-order views on spatial variations in erosion in several tectonic settings [Lavé and Avouac, 2001; Kirby and Whipple, 2001; Snyder et al., 2000].

[67] Here, in order to assess the most appropriate incision law, we initially search for the exponent ratio $\mathrm{m} / \mathrm{n}$ that best describes river profiles in the San Gabriel Mountains. On the basis of slope-area relations for the different morphotectonic regions (Figure 14), we find consistent scaling behavior between $1 \mathrm{~km}^{2}$ and $400 \mathrm{~km}^{2}$, with the slope of the power law ranging between $-0.37 \pm 0.03$ and $-0.44 \pm 0.04$. The intercept differs for each region by a maximum factor of $2-3$. Whereas the slope/area exponent does not clearly discriminate among various fluvial incision models [Whipple and Tucker, 2002], these exponent ratios indicate that longitudinal river profiles, if dictated by a detachment-limited incision model, are most consistent with the unit stream power or the shear stress $(\tau)$ model. They do not, however, define an absolute value for $n$. Following Lavé and Avouac's [2001] approach, we prefer the shear stress model as a proxy for fluvial incision rate:

$$
\dot{i}=K_{S}\left(\tau-\tau_{0}\right),
$$

where $\tau_{0}$ is a threshold value for mechanical abrasion of the river bed [Howard et al., 1994; Lavé and Avouac, 2001] and
$K_{S}$ depends on variables, such as lithology, sediment flux, and climate.

\subsection{Shear Stress and Incision Rate Computation}

[68] To derive the shear stress in the fluvial network, we initially estimate the slope and discharge along the fluvial network. Slope was derived from a $30 \mathrm{~m}$ digital elevation model (DEM) that was filtered to suppress local sinks and smooth associated steps. Flood discharge was computed, taking into account average precipitation (Figure 2a) and according to a power law function of the catchment area expressed by relation (1). Sediment production in the San Gabriel Mountains, and in particular for the San Gabriel dam (Figure 7), shows that two thirds of the sediment accumulated following the six major rainstorms since 1938. We thus infer that the most efficient characteristic flood for sediment transport is also close to the 10 year event: This could, therefore, also represent the most efficient flood for exposing bedrock to incision. Following Lavé and Avouac's [2001] approach, the 10 year return daily peak flow is chosen as the representative discharge. Using the classical relation $W \propto Q^{0.5}$ for alluvial rivers [Leopold, 1994] and after calibration using sites measured on San Gabriel aerial photos, we roughly established that width scales with discharge in the bedrock rivers of the study area such that $W=2 Q^{0.5}$.

[69] Lavé and Avouac [2001] used the Shields stress, instead of shear stress, in order to account for significant mean gravel size change along the $200-400 \mathrm{~km}$ long Transhimalayan rivers. Here, given the more reduced size of the study area and in absence of systematic measurements, we neglect gravel size variations. In the North Fork of the San Gabriel River, fluvial material in terraces and the present channel displays median gravel sizes of $30 \mathrm{~mm} \leq$ $D_{50} \leq 110 \mathrm{~mm}$, in close correspondence with usual values along most mountain rivers [e.g., Mezaki and Yabiku, 1984; Kodama, 1994; Heller et al., 2001]. We initially assume a median gravel size $D_{50}=50 \mathrm{~mm}$ along the San Gabriel fluvial network. Lavé and Avouac's [2001] Shields stress equation then simply reduces to a shear stress equation like equation (18) such that the final expression for incision rate $i$ is therefore

$$
\dot{i}=K_{S}\left(0.92 \bar{P}^{0.3} A^{0.28} S^{0.7}-26\right) .
$$

[70] Note that unlike most other formulations for incision, we can incorporate spatial variations in mean precipitation over the watershed $\bar{P}$ based on our analysis of the rain gauge records (Figure 2). In expression (19) the coefficient $K_{S}$ primarily reflects the erodibility of the bedrock and the hydroclimatic regime. If we exclude the frontal zone north of San Fernando, where Cenozoic sediments are exposed, San Gabriel lithologies are mostly intrusive with minor amounts of schist and gneiss. These lithologies are probably as strong as, or even stronger than, Himalayan gneissic lithologies: Pebble abrasion experiments indicate, for example, that granites abrade 2-3 times slower than gneisses [Kuenen, 1956]. Spotila et al. [2002] classified the different rock units cropping out in the San Gabriel according to their inferred resistance to erosion, but this qualitative classification cannot be directly translated in terms of an 


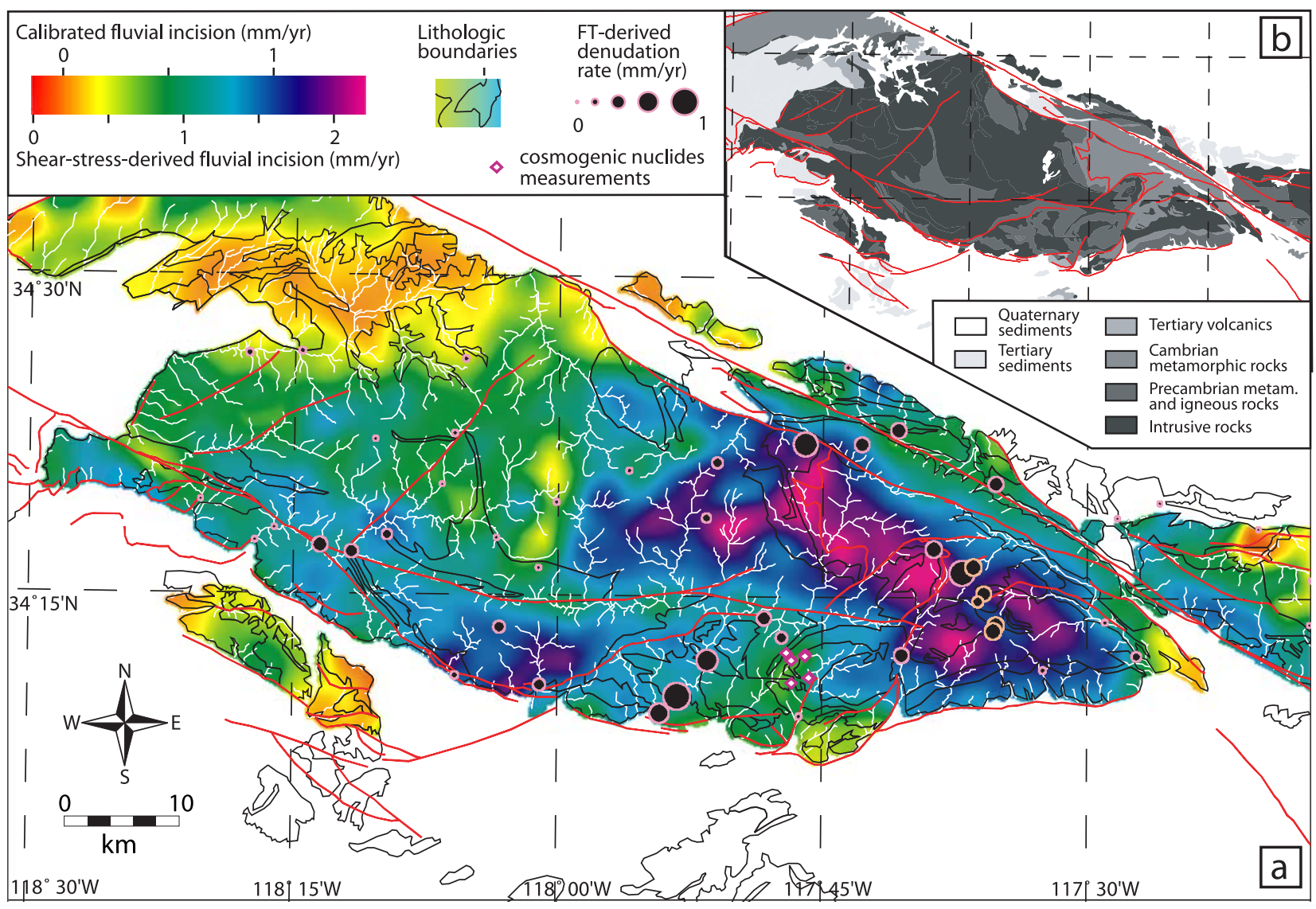

Figure 15. (a) Interpolated map of fluvial incision according to Shields stress computation along the drainage network for catchments $>1 \mathrm{~km}^{2}$ where fluvial processes become predominant (white arcs) and after interpolation and smoothing (3-km-wide circular running window) between the drainage network. (b) A similar erodibility coefficient has been applied to metamorphic, igneous, and volcanic units: A posteriori, this hypothesis appears reasonable because no clear correlation appears between fluvial incision rate and lithology. Incision rate values can also be visually compared to long-term denudation as deduced from apatite fission track analysis [Blythe et al., 2000] (pink circles) and from five apatite (U $\mathrm{Th}) / \mathrm{He}$ ages [Blythe et al., 2002] (orange circles), assuming a geothermal gradient of $30^{\circ} \mathrm{C} \mathrm{km}^{-1}$. The most striking feature appears to be the agreement between both sets of data for (1) the western block, where subdued fluvial incision values correspond to minor long-term denudation since the early Cenozoic, and (2) the Mount Baldy-Cucamonga block, where maximum incision values correspond to the rapid long-term denudation rate. The San Dimas and Big Dalton watersheds, sites with denudation rates determined from cosmogenic nuclides [Heimsath, 1999], are indicated (diamonds) (see text for discussion).

erodibility coefficient. In the absence of systematic measurements for each lithology we assume a uniform value of $K_{S}=6 \mathrm{~mm} \mathrm{yr}^{-1}$, a value of the same order as for Himalayan gneisses. On the other hand, hydroclimatic regimes are very different in the two areas. Himalayas are exposed to long rainy periods during the monsoon, and flood durations are far longer than those during San Gabriel winter storms (section A3). For example, the duration of high-discharge floods is $2-5$ times shorter in the San Gabriel rivers than in the Himalayan rivers (see section A3) and should therefore produce less incision per flood event.
[71] Nevertheless, we initially assume a uniform value of $K_{S}=6 \mathrm{~mm} \mathrm{yr}^{-1}$ for the entire San Gabriel region (Figure 15), except for the Cenozoic sediments, which we exclude from further analysis. Despite large uncertainties on the absolute values of incision rates, the shear stress incision model provides a spatial image of relative variations between the different morphotectonic regions.

[72] On the basis of the area-slope diagrams (Figure 14) and the apparent spatial threshold for the influence of debris flows (Figure 9), we consider fluvial incision to be the dominant control on base-level lowering in drainage areas 
$\leq 1 \mathrm{~km}^{2}$. Therefore shear stress and the incision rate have been computed only for the fluvial network downstream of a $1 \mathrm{~km}^{2}$ threshold (white network in Figure 15). In order to create an image of spatial variations in the mean river incision rate, values were interpolated between the fluvial channels and then smoothed with a $3 \mathrm{~km}$ wide circular running window, assuming that rock uplift variations primarily occur at longer wavelengths, whereas apparent incision variations at shorter scales are mainly due to DEM inaccuracy, local lithologic effects, or channel slope irregularities due stochastic processes, such as landslides, sediment waves, or terrace reincision.

[73] The resultant incision map displays a consistent pattern (Figure 15) within different morphotectonic regions separated by major faults: a rapidly eroding region at a rate of $1.5-2 \mathrm{~mm} \mathrm{yr}^{-1}$ matches the Mount Baldy-Cucamonga block (MBC, Figure 1); another rapidly eroding block $\left(1.5 \mathrm{~mm} \mathrm{yr}^{-1}\right)$ corresponds to the Central Sierra Madre block south of the San Gabriel fault; between these the Eastern Sierra Madre block displays a slower incision rate $\left(0.7 \mathrm{~mm} \mathrm{yr}^{-1}\right)$; and finally, the western and northern part of the San Gabriel Range yield the slowest incision rate. No obvious correlation is observed between fluvial incision rate and lithology: This suggests either that different lithologies offer a similar resistance to abrasion or/and plucking or that fluvial incision is more sensitive to limits imposed by the transport of sediments than to limits imposed by rock strength along the San Gabriel fluvial network.

[74] If Holocene debris production in the San Gabriel Mountains is interpreted as a first-order image of erosion rates at even longer timescales, then incision rates derived from the shear stress model clearly overestimate the landscape erosion rates (Figure 15). Derivation of reliable incision estimates from a shear stress model, however, requires accurate determination of at least three parameters: median gravel size, lithologic erodibility, and the role of flood duration in total incision [Lavé and Avouac, 2001]. Alternatively absolute incision rates require an independent calibration of the coefficient $K_{S}$ in equation (19). Focusing on debris production behind dams, where rates are more consistent than in small debris basins, a linear regression between long-term debris production rates (with natural fire ignition) and average incision rates at the scale of the corresponding watershed provides a calibration factor of $0.7 \pm 0.16$ (mean slope of the linear regression (Figure 16a)) to derive a calibrated incision rate (upper scale (Figure 15)). The regression intercept is close to zero and does not indicate that the threshold value $\tau_{0}$ needs to be significantly modified.

[75] After calibration, local incision rates can be compared to the Cenozoic denudation rates as depicted by fission track thermochronology [Blythe et al., 2000; Spotila et al., 2002]. Calculated incision rates are comparable to the maximum values of apparent landscape denudation rates (Figure 17) [see also Spotila et al., 2002, Figure 7b], i.e., where late Cenozoic denudation has been sufficient to exhume rocks located below the closure temperature of $\sim 110^{\circ} \mathrm{C}$ at the initiation of the present morphotectonic regime at $\sim 5-6 \mathrm{Ma}$.

[76] Without an independent calibration of incision rates, the river network can not be shown to erode at the same rate as the hillslopes. Several arguments support such a

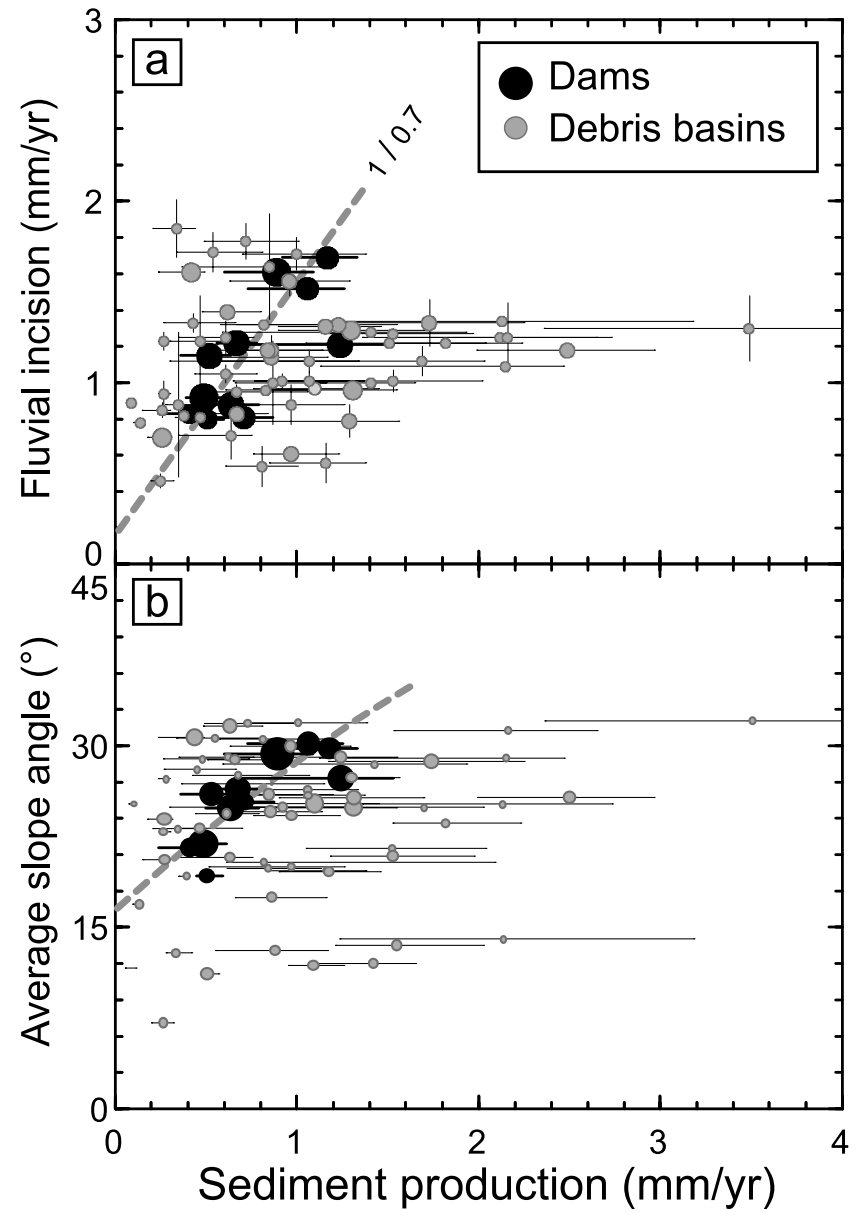

Figure 16. Comparison between the sediment production with a "natural" fire ignition rate in debris basins (gray circles) and dams (black circles) and (a) the average fluvial incision rate in their respective watersheds as derived from the incision map (Figure 15) and (b) the average local slope over the contributing watershed (computed on a $3 \times 3$ cells basis). Debris production rate values in dams are relatively well correlated to fluvial incision or the average local slope. By contrast, sediment production rate values in debris basins are more scattered, as already observed in Figures 5 and 8, even if fire corrections significantly reduce the scatter. To perform a linear regression (dotted line) between sediment production and fluvial incision or average slope, only the dam data and the mountainous parts of the Devil's Gate (131) and Eaton Wash (139) watersheds have been used.

scenario; however, the coherence of the stream concavity (ratio $n / m$ ) among different tectonic blocks suggests that the river network is probably close to equilibrium and that the rough correlation between debris production rates in dams and calculated incision rates suggests some type of persistent equilibrium between hillslope erosion and fluvial downcutting.

\section{Discussion}

\subsection{Hillslope Erosion Processes}

[77] The preceding analysis provides an overview of erosion on the hillslopes of the San Gabriel Mountains 


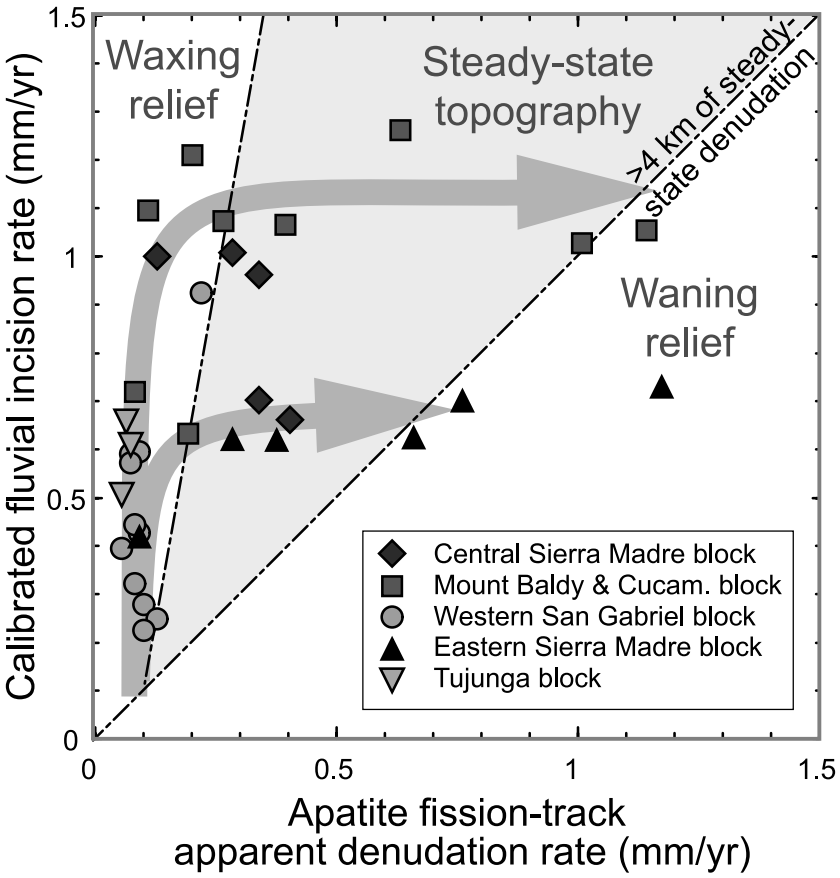

Figure 17. Comparison between the long-term denudation rate as deduced from fission track analysis [Blythe et al., $2000,2002]$, assuming a geothermal gradient of $30^{\circ} \mathrm{C} \mathrm{km}^{-1}$ and vertical erosion, and the corresponding recalibrated fluvial incision rate (Figures 15 and 16a). These ratios define fields related to pre- and post-steady-state conditions. Only part of the Mount Baldy-Cucamonga block and East Sierra Madre block have encompassed enough denudation to reach some kind of steady state of the isotherms, for which the FT denudation rate is similar to fluvial downcutting. For the other blocks, in particular, the central Sierra Madre block, denudation has been sufficient for the topography to reach some equilibrium, as observed from the uniform slope of the river gradient area relationship (Figure 14), but has been lower than the minimum required exhumation $(\sim 4 \mathrm{~km})$ for rocks to reach the surface that were located near the $110^{\circ} \mathrm{C}$ isotherm at the initiation of the present denudational regime.

during the twentieth century. Natural erosion has been augmented, in particular in the southern front, by the disturbances produced by human-ignited fires. Documented erosion processes following fires include dry and wet ravel of unprotected soil, transport by small debris flows, and shallow, soil-involved landslides. Locally, during the past century, the sediment contribution due to fire may represent up to $80 \%$ of the total sediment production in debris basins. In watersheds above dams the fire-induced contribution appears lower but is probably underestimated due to the damping effect of sediment storage in larger fluvial networks. We suspect that our fire corrections are only minimal: equation (3) does not fully account for the loss of root strength and the resultant enhancement of shallow landslides after fires [Benda and Dunne, 1997a]. Even without fully adequate model for the impact of fire, fired-induced sediment production by various forms of soil erosion is the dominant contributor to twentieth-century erosion. If we extrapolate observations from the San Dimas Experimental Forest [Rice et al., 1969; Rice and Foggin, 1971] to the entire San Gabriel region, storm-induced soil slippage and shallow landsliding together represent the second most important erosion process during the past century, whereas debris production by deep-seated landslides has been an order of magnitude lower than these two other processes.

[78] At longer timescales, i.e., before anthropogenic disturbance, surface and shallow erosion processes still appear dominant relative to bedrock landslides. Fission track analysis [Blythe et al., 2000] indicates apparent denudation rates ranging between 0.1 and $1 \mathrm{~mm} \mathrm{yr}^{-1}$ : These long-term values are lower than twentieth-century denudation but are consistent with sediment production after fire effects are subtracted (Figure 18). We thus suggest that erosion rates at the scale of both the twentieth century and the late Cenozoic provide a first-order estimate of average Holocene denudation rates. In that case, the long-term erosion by deep-seated landslides, even after addition of the contribution of major landslides and of seismically triggered landslides, can account for only $10-60 \%$ of the net erosion rate in the San Gabriel Mountains. Moreover, these contributions represent an upper bound because we have underestimated the revegetation time of the big landslides. The major contribution to erosion therefore remains surface and shallow processes: Depending on the natural fire frequency, superficial erosion of the unprotected soil after a fire represents $10-30 \%$ of the total erosion. About half of the total erosion is then attributed to shallow landslides and soil slippages by analogy with observations in the Big Dalton upper watershed during the past 50 years.

[79] If shallow landslides contribute strongly to debris production in the long term, rock must be converted to regolith and sediment fluxed to colluvial hollows at an equivalent or higher rate than landsliding removes it. In the San Dimas Experimental Forest, cosmogenic nuclide concentrations in river sand and on hillslopes provide an independent estimate of integrated hillslope erosion rates and of soil production (or bedrock weathering) rates, respectively [Heimsath, 1999]. The resultant hillslope erosion rates range from $0.25 \mathrm{~mm} \mathrm{yr}^{-1}$ to $0.45 \mathrm{~mm} \mathrm{yr}^{-1}$, whereas maximum rates of bedrock weathering and soil production on hillslopes in this area are $\sim 0.3 \mathrm{~mm} \mathrm{yr}^{-1}$ [Heimsath, 1999]. In the upper Big Dalton watershed, these cosmogenic rates compare well with long-term denudation rates by soil slippage of $\sim 0.4 \mathrm{~mm} \mathrm{yr}^{-1}$ (Figure 13c) but are lower than the fire-corrected debris sedimentation rate in Big Dalton or San Dimas dams (Figure 13c). Nonetheless, the overall equivalency between different estimates of erosion rates suggests that the methodologies employed here to estimate rates are reasonable.

[80] Whenever the long-term denudation rate exceeds the soil production rate, non-soil-dependent processes, such as deep-seated landsliding, must account for the deficit. Consequently, a key insight on the relative importance of erosional processes can emerge from documentation of soil production rates. In an area, such as the San Dimas Experimental Forest, where long-term erosion rates are relatively slow $\left(\sim 0.3-0.4 \mathrm{~mm} \mathrm{yr}^{-1}\right)$, rock-to-regolith conversion is sufficiently rapid to account for all observed erosion; that is, no involvement of unweathered bedrock is needed to balance the landscape erosion rates. To the extent 


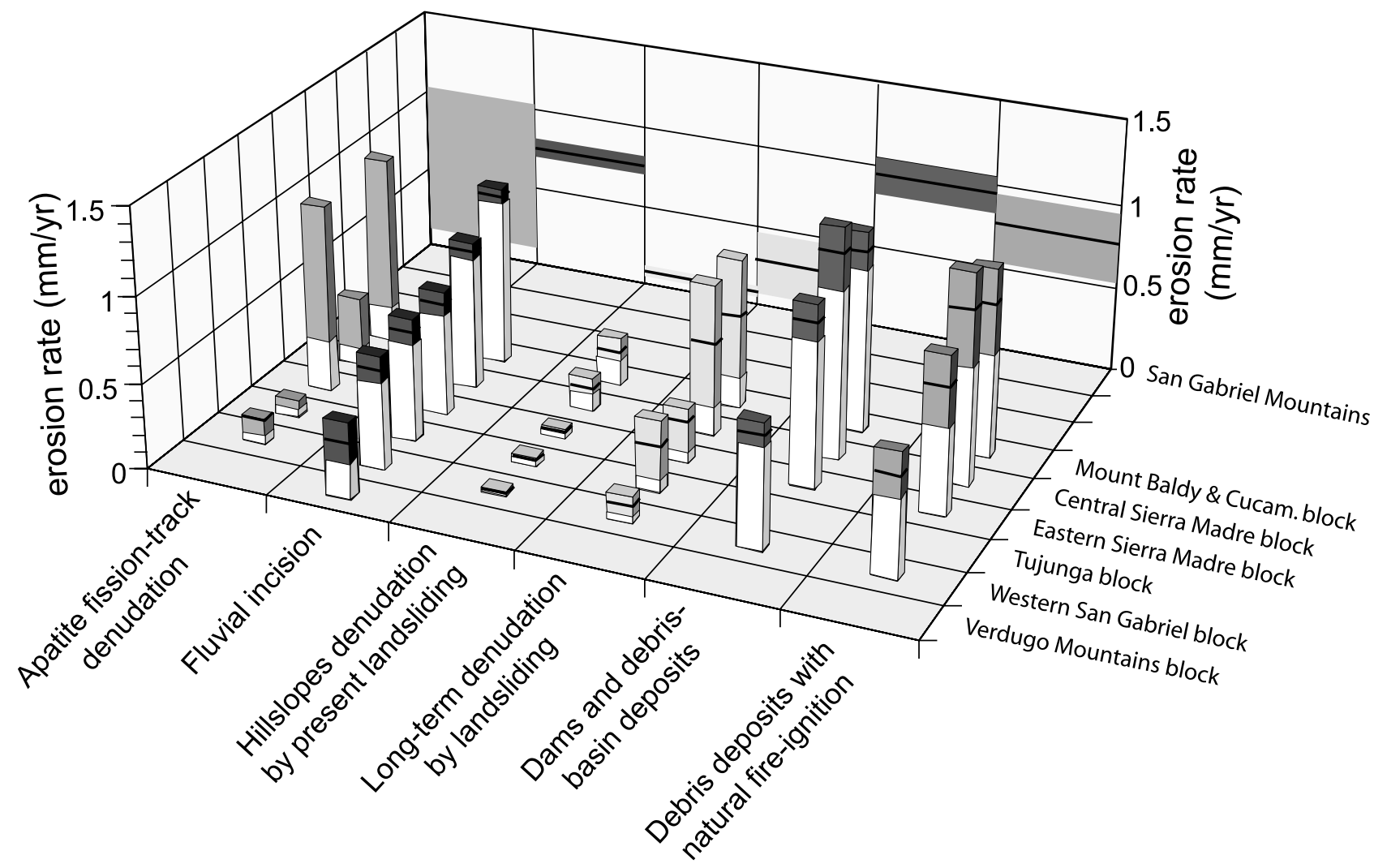

Figure 18. General comparison between the different estimates of short-term and long-term denudation rates in the five different morphotectonic units defined in the San Gabriel Mountains. Note that by contrast with Figures 5 and 8, average sediment production rates are volumetric averages.

that higher rates of rock-to-regolith conversion have not been documented here or elsewhere, $0.3-0.4 \mathrm{~mm} \mathrm{yr}^{-1}$ may represent an approximate threshold erosion rate, above which bedrock erosion on hillslopes via landslides or glaciers is required. Given that the Mount Baldy-Cucamonga and Central East Sierra Madre blocks (Figure 1a) appear to erode 2-3 times faster (Figure 15) than within the San Dimas Experimental Forest, deep-seated landsliding would be expected to play a more significant role in these areas, as suggested from our poorly constrained landslide counting results (Figure 18, Table 2).

[81] When mean hillslope angles over the contributing watershed are compared with nonfire sediment production in the debris basins (Figure 16b), no obvious correlation emerges. This independence is already observed in the slope exponent $\alpha_{2}=0$ in relation (3) that was obtained after inverting the debris basin data. In contrast, a significant correlation does exist between slope angles and the filling rates of dams, yielding a roughly linear relation:

$$
\dot{e}=0.04 \bar{S}-1.25,
$$

with the mean slope $\bar{S}$ in percent. This weak, but clear, dependency of erosion rates on average slope angles suggests that hillslopes have not reached their critical angle of repose everywhere in the landscape, as observed in more actively denuding mountains [Burbank et al., 1996]. For the San Gabriel Mountains, this reinforces the conclusion that erosion by deep-seated landslides is probably not the dominant process (Figure 18) and implies an important, if not major, contribution from slope-dependent processes. We therefore propose that the San Gabriel Mountains represent a transitional topography between ranges with rapid rock uplift and denudation that are dominated by deep-seated landslides and more slowly uplifting and eroding ranges that are fully soil mantled and strongly dominated by diffusive hillslope processes.

\subsection{Landscape Response Functions and} Stochastic Behavior

[82] Comparisons of climatic, fire, and debris production data sets indicate clearly that small and large watersheds have dissimilar responses. The observation that, after the 1965 storm season, debris production in the Big Dalton watershed was 4 times higher than hillslope erosion by soil slippage [Rice et al., 1969; Rice and Foggin, 1971] suggests, for example, that large volumes of sediment were remobilized by the flood from within fluvial channels. Such temporary storage could result from debris production on hillslopes following the 1960 fire (Figure 13) that completely burned the watershed. In contrast, the similarity between debris production and erosion by soil slippage after 1969 storm suggests that most of the stored sediments had been flushed out of the channels during the previous 1965 and 1966 storms. This "inertial" behavior, as described in section 3.3, leads to a temporal mismatch between fires, sediment production, storms, and sediment delivery in higher-order catchments, whereas in small catchments the temporal correlation is stronger because minor storms can generate debris flows that reach the debris basins where they 
are recorded. At a longer timescale a similar geomorphological response to fire has been documented in Yellowstone National Park [Meyer et al., 1992]: Dry periods with higher fire frequency promote both proximal fan aggradation and the resultant partial sediment storage in first-order and second-order channels, whereas during wetter periods the sediments are removed from alluvial fan storage and transported down high-order channels.

[83] Whatever the considered erosion processes, we can identify clear stochastic and nonlinear behavior. The occurrence of deep-seated landslides is a stochastic process, whether the slides are climatically or seismically triggered. Moreover, as long as our calculated slope exponent (equation (10)) is not too biased by poorly known revegetation times, major export of sediment is linked to rare and large landslide events. The stochastic nature of heavy precipitation also underpins triggering of shallow landslides. In the San Gabriel Mountains, however, and in contrast to settings with lower denudation rates [e.g., Kirchner et al., 2001], erosion is not dominated by the very rare and large events: The dependency of soil slippage rates on precipitation suggests that half of the denudation is produced by storms with a return period $<15-20$ years (Figures $13 \mathrm{~b}$ and $13 \mathrm{c}$ ). This relationship, however, is far from linear. Despite lower precipitation, the 1965/1966 storm season produced four times more soil slippage than the $1966 / 1967$ storm season: Either instantaneous rain intensity has more influence than the 24 hour average precipitation (we have no instantaneous precipitation record to validate such a scenario) [e.g., Caine, 1980; Cannon and Ellen, 1985; Wieczorek, 1987] or many hollows and outcrops susceptible to slippage failed during the 1965/1966 storm season, and sediment refill was insufficient to enable new soil failures during 1966/1967 storm season. The intensity of erosion by shallow landslides would therefore have significant dependence on the overall history of soil cover [Benda and Dunne, 1997a]. Finally, the stochastic nature of fire is also clearly transmitted through the sediment flux: In some cases, the equivalent of more than 50 years of background denudation can be provided to low-order channels in just one season.

[84] The stochastic character of hillslope processes and sediment delivery to fluvial networks is probably amplified as both erosion rate and deep-seated landslide contributions increase. The short-term impact of large events on the detrital load poses a challenge to attempts to calculate long-term erosion rates from suspended loads in mountainous rivers [see also Kirchner et al., 2001], cosmogenic nuclides in river sands, and most types of provenance analysis that assume steadily producing source areas. Above a minimum catchment size of a few $\mathrm{km}^{2}$, however, a river acts as an efficient filter that smoothes and delays the sediment supply. In such circumstances the fluvial network becomes almost immune to the stochastic behavior of hillslope processes but remains subject to the stochastic nature of large floods (the most efficient flood being approximately the decadal flood).

\subsection{Long-Term Evolution, Steady State, and Coupling Between Tectonics and Climate}

[85] In the context of a dynamic equilibrium, steady state can be defined in terms of topography, fluxes of material into and out of a range, and thermal conditions [Willett and
Brandon, 2002]. In a flux steady state, erosion rates should balance rock uplift rates, whereas in a topographic steady state, denudation of hillslopes should occur at the same rate as fluvial incision (to maintain constant relief) and should balance rock uplift rates (to maintain mean elevation). For the San Gabriel Mountains, such equilibrium has been partly tested by comparing debris basin sediment production rates with the mean value of the fluvial incision rates in the same catchment (Figure 16a). These rates are of the same order of magnitude, suggesting a rough balance. Because each rate has large uncertainties associated with it, however, an equilibrium can not be definitively assessed. In contrast, relative values are less sensitive to many sources of errors. The correlation for watersheds with dams between nonfire debris production rates during the past century and average late Quaternary fluvial incision rates indicates no obvious disequilibrium between the fluvial network and entire landscape. Erosion has probably been sufficient for the river channels and the hillslopes to attain equilibrium profiles.

[86] At late Cenozoic timescales, incision rates are comparable to the maximum values of long-term landscape denudation as deduced from fission track analyses [Blythe et al., 2000], assuming a geothermal gradient of $\sim 30^{\circ} \mathrm{C} \mathrm{km}^{-1}$ (Figures 17 and 18 ). However, most of the apparent denudation rates derived from cooling ages are much smaller than late Quaternary fluvial incision rates. Our preferred interpretation is the following: The present morphotectonic and erosive regime initiated with the most recent stage of compression in the Los Angeles basin area beginning $\sim 5 \mathrm{Ma}$. Wherever mean erosion rates have been slower than $\sim 0.6 \mathrm{~mm} \mathrm{yr}^{-1}$, insufficient erosion has occurred to expose rocks that would have cooled below the fission track annealing temperature of $\sim 110^{\circ} \mathrm{C}$ since 5-6 Ma. Only 5 out of $>40$ fission track sites yield ages $\leq 5 \mathrm{Ma}$. Similarly, only a few $(\mathrm{U}-\mathrm{Th}) / \mathrm{He}$ ages (closure temperature $\sim 70^{\circ} \mathrm{C}$ ) yield ages younger than the late Miocene. Consequently, most of the apparent denudation rates based on cooling ages are not representative of Quaternary denudation. Comparison of denudation rates based on our fluvial incision model with those derived from the fission track ages (Figure 17) suggests that only parts of the Mount Baldy-Cucamonga and East Sierra Madre blocks have sustained enough denudation $(>3-4 \mathrm{~km})$ to approach a thermal steady state, for which the fission track denudation rate is similar to fluvial downcutting rate. For the other blocks and, in particular, the central Sierra Madre block, denudation has been sufficient for the topography to attain some equilibrium form but insufficient to approach a thermal steady state. For this block the geomorphic denudation rate must have increased recently, as expected for a growing topography, or alternatively, deformation could have migrated southward since $5 \mathrm{Ma}$. Several other areas have clearly not yet attained a topographic steady state. For example, in the northwest and central part of the range, lowrelief topographic remnants, such as Chilao Flat (yellow green spot at $117^{\circ} 45^{\prime} \mathrm{W}$ and $34^{\circ} 20^{\prime} \mathrm{N}$, Figure 15 ), show that channel gradients and hillslopes have not yet adjusted to the local rock uplift rate. Such areas represent a "waxing" phase of steady state topography (Figure 17). In contrast, a "waning" phase may be represented by the eastern Sierra Madre block. Here fission track data indicate high, long- 
term denudation rates (Figure 15), whereas fluvial incision, debris production, landslide mapping, and cosmogenic measurements suggest a twofold decrease of the late Quaternary erosion rates with respect to the long-term rates.

[87] From this study we lack sufficient data to assess a possible coupling between tectonics and climate or the development of topographic relief driven by climatic effects [Molnar and England, 1990]. However, two necessary conditions for this coupling are here verified. First, the precipitation map clearly depicts orographic effects (Figure 2), in which topography strongly influences precipitation in the San Gabriel Mountains. Maximum precipitation occurs along the south side of the highest peaks of the Sierra Madre and Mount Baldy-Cucamonga blocks, sites that also correspond to the peaks in denudation rate (Figure 15). Second, most of the erosion and incision processes that drive denudation in the San Gabriel Mountains show a rain intensity dependency. For example, both our sediment flux equation (3) and the soil slippage relation (Figure 13b) depend on precipitation with a power exponent $>1$. Sediment transport and fluvial incision as related to shear stress depend on flood discharges and thus on precipitation intensity. Moreover, if the time-integrated erosive action is proportional to flood duration, then both the amplitude of the flood (i.e., the maximum daily discharge in our model) and its duration determine incision rates. The whole hydrologic regime is therefore expected to have an extensive and profound impact in terms of denudation, lowering of base level, and, consequently, the maximum elevation of the mountain ranges. In sum, these positive feedbacks between climate and topography represent favorable preconditions for an effective coupling between tectonics and climate.

\section{Conclusions}

[88] Interactions among tectonics, erosion, and climate determine the evolution of mountain belts toward a potential flux steady state. Despite the conceptual appeal of a steady state, tests of its existence require difficult-to-obtain demonstrations of the temporal persistence of fluxes into and out of the orogen over intervals of $10^{5}-10^{7}$ years [Burbank, 2002]. Few studies have succeeded in such tests. An alternative strategy is to compare spatial patterns of longterm and short-term rates of erosion, from which either a temporal steadiness can be inferred when the rates are balanced or waxing/waning topographic states can be interpreted from mismatched rates.

[89] The Transverse Ranges of southern California present a unique opportunity to evaluate present and past denudation rates. The existence of $>50$ fission track and (U - Th)/He dates [Blythe et al., 2000] provides a dense array of cooling ages that serve as indicators of long-term denudation rates. Because the San Gabriel Mountains impinge on a metropolitan area, a remarkable suite of observations on rates and processes of erosion has been collected over the past century. These serve to delineate the geomorphic regime with unprecedented clarity. An extensive, frequently monitored network of debris basins and dams yields estimates of the total sediment load exiting the orogen since the 1920s. For precipitous terrain in rapidly denuding mountains where debris flows deliver most sediment to the range front, it is particularly valuable (and uncommon) to be able to measure the bedload rather than just the suspended load. In addition to a broad array of rain and stream gauges used to monitor precipitation and runoff over the past century, aerial photographs and satellite images have documented the history of landslides and fires.

[90] In this study we have exploited this remarkable database to estimate denudation rates and patterns in the Transverse Ranges based on methods encompassing different spatial and temporal scales. Each method incorporates inherent assumptions or biases. For example, due to the stochastic nature of landsliding, reliable measurement requires an extended time window, whereas the methodology using repeat aerial photographs also depends on calibrating vegetation regrowth rates at short (decadal) intervals. Similarly, calculations of sediment budgets in dams and debris basins require a delicate, yet poorly constrained, subtraction of anthropogenic erosional effects attributable to fire. A better understanding of the physics of fluvial incision as well as an independent calibration of the fluvial shear stress method are needed to estimate river erosion.

[91] Despite these limitations, our analysis in the San Gabriel Mountains is consistent with the following.

[92] 1. Shallow landsliding on soil-mantled slopes accounts for about half of the hillslope erosion, whereas deep-seated (bedrock) landsliding commonly contributes $\leq 1 / 3$ of the total flux.

[93] 2. Fires followed by intense storms typically generate the largest sediment fluxes.

[94] 3. Anthropogenic fires have accelerated the rate of erosion up to fourfold within small, steep catchments abutting populous areas.

[95] 4. The fluvial network exerts a buffering effect on hillslope sediment supply such that significant quantities of sediment are stored in higher-order channels and are only moved during large, infrequent storms. Consequently, a temporal decorrelation at short timescales (e.g., annual time series) occurs between hillslope sediment production and export of that sediment from the range itself.

[96] 5. In relatively slowly denuding catchments $(\leq 0.3 \mathrm{~mm}$ $\left.\mathrm{yr}^{-1}\right)$, rock-to-regolith conversion can be sufficiently rapid to permit soil-related processes, such as shallow landsliding or wet and dry ravel, to dominate all significant erosion. As erosion rates progressively surpass rock-to-regolith conversion rates, bedrock landslides play a proportionally more important denudational role.

[97] 6. In contrast to some rapidly denuding ranges, such as the Southern Alps of New Zealand, where erosion rates exceeding $2 \mathrm{~mm} \mathrm{yr}^{-1}$ are typical, the San Gabriel Mountains occupy an intermediate niche with erosion rates range from 0.1 to $1 \mathrm{~mm} \mathrm{yr}^{-1}$. As a result, the relative importance of soilinvolved versus bedrock-involved erosional processes varies among morphotectonic regions. Moreover, through a comparison of short-term and long-term erosion rates, regions that have experienced either accelerated or recent rock uplift can be distinguished from those for which a long-term balance persists or for which erosion rates are diminishing and the topography appears to be waning.

[98] 7. Finally, the use of multiple measures of denudation in the same landscape facilitates a more robust 


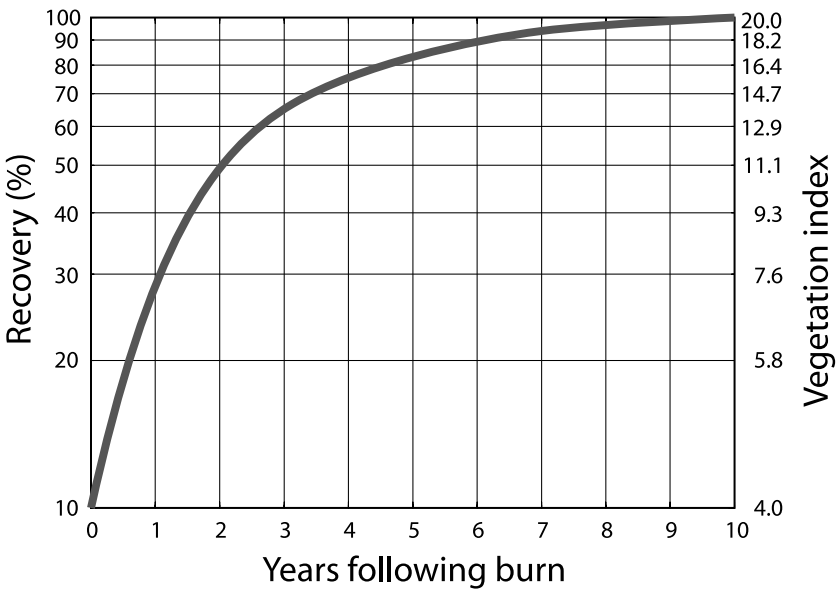

Figure A1. Vegetation growth recovery from $L A C F C D$ [1959]. After 10 years, bush vegetation has almost fully recovered from former fires. In our computation we assume that the vegetation index (Ve in equation (2)) varies in proportion with the growth recovery and reaches a value $\mathrm{Ve}=$ 20 after 10-12 years, when growth recovery is complete.

depiction of spatial and temporal variations in rates and processes than has commonly been achieved in the past.

\section{Appendix A}

A1. Vegetation Regrowth Rate for Burned Watersheds

[99] Several studies by the $L A C F C D$ [1959] estimate vegetative recovery rates after fires. They indicate a rapid regrowth in the first 3 or 4 years and show that complete revegetation normally occurs in $<12$ years (Figure A1). On the right axis is the approximate vegetation index (Ve) used to calibrate fire-related sediment production.

\section{A2. Calibration of Keefer and Wilson's [1989] Volumetric Landslide Law From the San Fernando Earthquake}

[100] For the San Gabriel Mountains we try to calibrate the parameters in equation (12) by considering the volume

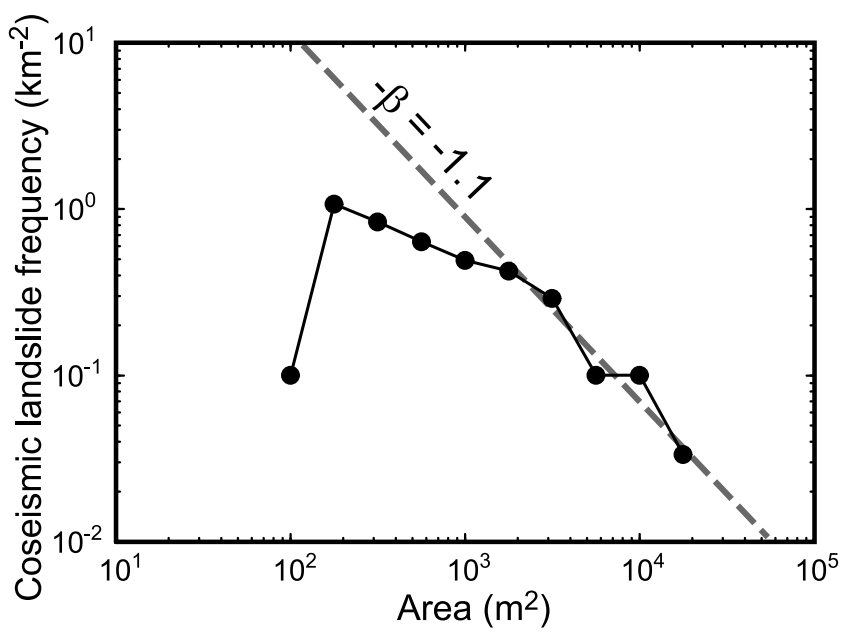

Figure A2. Cumulative distribution of the landslides triggered by the San Fernando earthquake. For reference the average slope for the entire San Gabriel magnitudefrequency distribution of landslides (Figure 11) is shown.
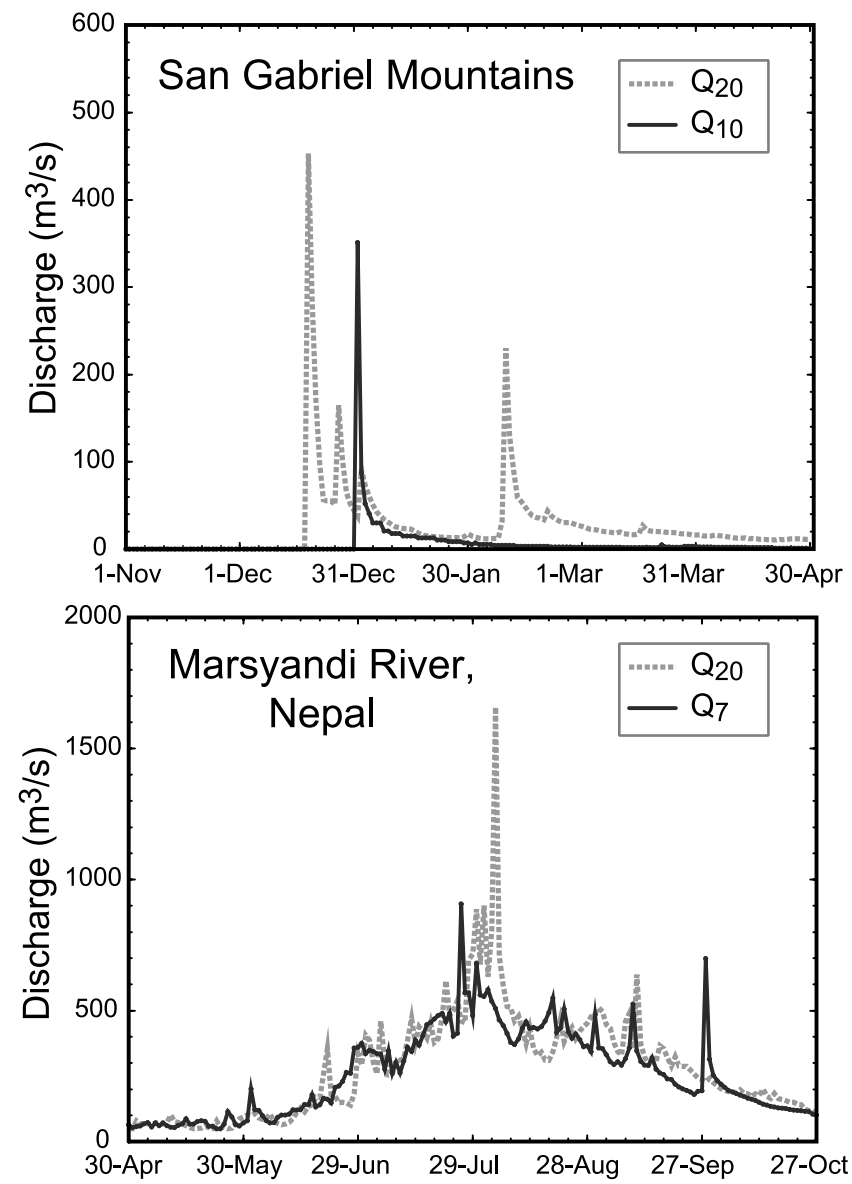

Figure A3. Characteristic floods in the (top) San Gabriel Mountains (Santa Gabriel River; $A=500 \mathrm{~km}^{2}$ ) and in (bottom) central Nepal (Marsyandi River; $A=2000 \mathrm{~km}^{2}$ ). For the San Gabriel River the 1909-1910 and 1921-1922 winter flood seasons were chosen as representative of the 10-year-return and 20-year-return daily peak flows $\left(Q_{10}\right.$ and $Q_{20}$, respectively). For the Marsyandi River the 1981 and 1974 flood seasons were chosen as representative of the 7-year-return and 20-year-return daily peak flows $\left(Q_{7}\right.$ and $Q_{20}$, respectively).

of debris produced by landslides during $M=6.5$ San Fernando 1971 earthquake. We used Morton's [1975] landslide mapping to infer the total volume of landslides triggered by this earthquake as $\sim 10^{7} \mathrm{~m}^{3}$. Furthermore, we modified his mapping by applying a correction factor of $0.2<k<0.5$ (i.e., $\sim 2-5 \times 10^{6} \mathrm{~m}^{3}$ for the total eroded volume) to adjust for the fact that both landslide scars and related debris lobes were mapped as a single feature and that some landslides are slowly moving. Such landslides moved only a few meters during this earthquake and probably need several seismic events or major storms to collapse and export their material toward the fluvial network. This correction factor results from comparison of Morton's [1975] mapping of landslides with our own mapping on aerial photos taken just after the earthquake. With this methodology, we could limit the parameter range to $-3.7<\gamma<-3.2$ (equation (12)). Notably, the cumulative distribution of the coseismic landslides (Figure A2) displays the same relationship as the storm-triggered landslides: In 
a power law relationship the slope exponent is roughly similar to $\beta=1.1$.

\section{A3. Comparison of the Flood Duration in the San Gabriel Mountains and in the Central Himalayas}

[101] Hydroclimatic regimes contrast strongly between the Himalayas, where the incision law was previously calibrated [Lavé and Avouac, 2001], and the San Gabriel Mountains. The Himalayas experience long rainy periods during monsoon months, and flood durations are longer than those during San Gabriel winter storms (Figure A3). Using daily discharges, we define the flood duration as the interval for which the discharge is $>0.5$ times the maximum daily discharge in the year. Accordingly, based on a 20 year record for a $2000 \mathrm{~km}^{2}$ catchment of the Marysandi River in Nepal, the high flood period persists for 3 and 10 days for $Q_{20}$ and $Q_{7}$, respectively. On the basis of 30-70 years of discharge records on 10 undammed catchments in the San Gabriel Mountains, the flood duration is nearly constant at $\sim 2$ days and is independent of the size of the drainage area, i.e., from 10 to $400 \mathrm{~km}^{2}$. Hence flood durations are, on average, $1.5-5$ times $\left(Q_{20} \geq Q \geq Q_{7}\right)$ shorter in the San Gabriel than in the Nepalese Himalayas. Bedrock incision efficiency, i.e., the instantaneous incision rate integrated over the flood duration, may also be comparably reduced in the San Gabriel Mountains with respect to the Himalayas.

[102] Acknowledgments. We are very grateful to the Los Angeles County Department of Public Works for their assistance and for kindly sharing aerial photos, debris basin and dam data, ArcView covers of fire history, and climatic and hydrologic data of Los Angeles county. We are particularly indebted to Robert Larson and Michael Bohlander. The manuscript benefited from thorough reviews and comments by J. Spotila and an anonymous reviewer. Our reflections on erosion processes at work in the San Gabriel Mountains also benefited from fruitful discussions with A. Meigs, D. Morton, and P. Sadler. This project was funded by NASA grant NAG5-7646. We thank Penn State, the Laboratoire de Géodynamique des Chaînes Alpines (LGCA-CNRS), and UCSB for their support.

\section{References}

Anderson, R. S. (1994), Evolution of the Santa Cruz Mountains, California, through tectonic growth and geomorphic decay, J. Geophys. Res., 99 , 20,161-20,179

Aschmann, H. H. (1959), Evolution of a wild landscape and its persistence, Ann. Assoc. Am. Geogr., 49, 35-56.

Atwater, T., and J. Stock (1998), Pacific-North America plate tectonics of the Neogene southwestern United States: An update, Int. Geol. Rev., 40(5), 375-402.

Avouac, J. P., and E. B. Burov (1996), Erosion as a driving mechanism of intracontinental mountain growth, J. Geophys. Res., 101, 17,74717,769

Barth, A. P. (1990), Mid-crustal emplacement of Mesozoic plutons, San Gabriel Mountains, California, and implications for the geologic history of the San Gabriel terrace, Mem. Geol. Soc. Am., 174, 33-45.

Benda, L., and T. Dunne (1997a), Stochastic forcing of sediment supply to channel networks from landsliding and debris flow, Water Resour. Res., 33, 2849-2863

Benda, L., and T. Dunne (1997b), Stochastic forcing of sediment routing and storage in channel networks, Water Resour. Res., 33, 2865-2880.

Bjorklund, T., K. Burke, H. Zhou, and R. S. Yeats (2002), Miocene rifting in the Los Angeles basin: Evidence from the Puente Hills half-graben, volcanic rocks, and P-wave tomography, Geology, 30, 451-454.

Blythe, A. E., D. W. Burbank, K. Farley, and E. Fielding (2000), Structural and topographic evolution of the central Transverse Ranges, California, from apatite fission-track, (U-Th)/He and DEM analyses, Basin Res., 12, $97-114$.

Blythe, A. E., M. A. House, and J. Spotila (2002), Low temperature thermochronology of the San Gabriel and San Bernardino Mountains, southern California: Constraining structural evolution, in Contributions to Structural Evolution of the Southwestern United States: Boulder Colorado, edited by A. Barth, Geol. Soc. Am. Spec. Pap., 365, 231-250.
Booker, F. A., W. E. Dietrich, and L. M. Collins (1993), Runoff and erosion after the Oakland firestorm, Calif. Geol., 46, 159-173.

Bull, W. (1991), Geomorphic Response to Climatic Change, 326 pp., Oxford Univ. Press, New York.

Burbank, D. W. (2002), Rates of erosion and their implications for exhumation, Mineral. Mag., 66, 25-52.

Burbank, D. W., J. Leland, E. Fielding, R. S. Anderson, N. Brozovic, M. R. Reid, and C. Duncan (1996), Bedrock incision, rock uplift and threshold hillslopes in the northwestern Himalayas, Nature, 379, 505-510.

Caine, N. (1980), The rainfall intensity duration control on shallow landslides and debris flows, Geogr. Ann., 62A, 23-27.

Cannon, S. H., and S. D. Ellen (1985), Rainfall conditions for abundant debris avalanches in the San Francisco Bay region, California, Calif. Geol., 38, 267-272.

Crowell, J. C. (1962), Displacement along the San Andreas fault, California, Geol. Soc. Am. Bull., 71, 1-61.

Densmore, A. L., and N. Hovius (2000), Topographic fingerprints of bedrock landslides, Geology, 28, 371-374.

Dolan, J. F., K. Sieh, T. K. Rockwell, R. S. Yeats, J. Shaw, J. Suppe, G. J. Huftile, and E. M. Gath (1995), Prospects for larger or more frequent earthquakes in the Los Angeles metropolitan region, Science, 267, 199205.

Foley, M. G. (1980a), Quaternary diversion and incision, Dearborn River, Montana, Geol. Soc. Am. Bull., Part I, 91, 2152-2188.

Foley, M. G. (1980b), Bedrock incision by streams, Geol. Soc. Am. Bull., Part II, 91, 2189-2213.

Hancock, G. S., R. Anderson, and K. X. Whipple (1998), Beyond power: Bedrock river incision process and form, in Rivers Over Rock: Fluvial Processes in Bedrock Channels, Geophys. Monogr. Ser, vol. 107, edited by K. J. Tinkler and E. E. Wohl, pp. 35-60, AGU, Washington, D. C.

Harp, E. L., and R. W. Jibson (1996), Landslides triggered by the 1994 Northridge, California, earthquake, Bull. Seismol. Soc. Am., 86, S319S332.

Hauksson, E. (1994), The 1991 Sierra Madre earthquake sequence in southern California: Seismological and tectonic analysis, Bull. Seismol. Soc. Am., 84, 1058-1074.

Heimsath, A. M. (1999), The soil production function, Ph.D. thesis, 324 pp., Univ. of Calif., Berkeley.

Heller, P. L., P. E. Beland, N. F. Humphrey, S. K. Konrad, R. M. Lynds, M. E. McMillan, K. E. Valentine, Y. A. Widman, and D. J. Furbish (2001), Paradox of downstream fining and weathering-rind formation in the lower Hoh River, Olympic Peninsula, Washington, Geol. Soc. Am., 29, 971-974.

Hill, M. L., and T. W. Dibblee Jr. (1953), San Andreas, Garlock, and Big Pine faults, California: A study of the character, history and tectonic significance of their displacements, Geol. Soc. Am. Bull., 64, 443-458.

Hovius, N., C. P. Stark, and P. A. Allen (1997), Sediment flux from a mountain belt derived by landslide mapping, Geology, 25, 231-234

Howard, A. D., W. E. Dietrich, and M. A. Seidl (1994), Modeling fluvial erosion on regional to continental scales, J. Geophys. Res., 99, 13,97113,986 .

Huffines, G. R., and R. E. Orville (1999), Lightning ground flash density and thunderstorm duration in the continental United States: 1989-96, J. Appl. Meteorol., 38, 1013-1019.

Jennings, C. W., and W. Charles (1994), Fault activity map of California and adjacent areas with location and ages of recent volcanic eruptions, in California Geologic Data Map Ser., Map 6, Calif. Div. of Mines and Geol., Sacramento.

Jennings, C. W., and R. G. Strand (1969), Geologic map of California: Los Angeles sheet, Map XX, scale 1:25,0000, Calif. Div. of Mines and Geol., Sacramento.

Keefer, D. R., and R. C. Wilson (1989), Predicting earthquake-induced landslides, in Landslides in a Semi-arid Environment With Emphasis on Inland Valley of Southern California, edited by P. M. Sadler and D. M. Morton, Publ. Inland Geol. Soc., 2, 118-149.

Keller, E. A. (1986), Investigation of active tectonics: Use of surficial earth processes, in Active Tectonics, pp. 136-147, Natl. Acad. Press, Washington, D. C.

Kirby, E., and K. Whipple (2001), Quantifying differential rock-uplift rates via stream profile analysis, Geology, 29, 415-418.

Kirchner, J. W., R. C. Finkel, C. S. Riebe, D. E. Granger, J. L. Clayton, J. G. King, and W. F. Megahan (2001), Mountain erosion over 10 yr, 10 k.y., and 10 m.y. time scales, Geology, 29, 591-594.

Kodama, Y. (1994), Downstream changes in the lithology and grain size of fluvial gravels, the Watarase River, Japan: Evidence of the role of abrasion in downstream fining, J. Sediment. Res., Sect. A, 64, $68-75$.

Kooi, H., and C. Beaumont (1996), Large-scale geomorphology: Classical concepts reconciled and integrated with contemporary ideas via a surface processes model, J. Geophys. Res., 101, 3361-3386. 
Koons, P. O. (1989), The topographic evolution of collisional mountain belts: A numerical look at the southern Alps, New Zealand, Am. J. Sci., 289, 1041-1069.

Krammes, J. S., and L. F. Debano (1965), Soil wettability: A neglected factor in watershed management, Water Resour. Res., 1, 283-287.

Kuenen, P. H. (1956), Experimental abrasion of pebbles: 2. Rolling by current, J. Geol., 64, 336-368.

Lavé, J., and J. P. Avouac (2001), Fluvial incision and tectonic uplift across the Himalaya of central Nepal, J. Geophys. Res., 106, 26,561-26,593.

Leopold, L. B. (1994), A View of the River, 292 pp., Harvard Univ. Press, Cambridge, Mass

Long, C. J. (1996), Fire history of the central coast range, Oregon: A ca 9000 year record from little lake, M.S. thesis, Univ. of Oregon, Eugene.

Los Angeles County Department of Public Works (LACDPW) (1991), Hydrology manual, internal document, Alhambra, Calif.

Los Angeles County Flood Control District (LACFCD) (1959), Report on debris reduction studies for mountain watersheds of Los Angeles County, 164 pp., Los Angeles, Calif.

Meyer, G. A., S. G. Wells, R. C. Balling Jr., and A. J. T. Jull (1992), Response of alluvial systems to fire and climate change in Yellowstone National Park, Nature, 357, 147-150.

Mezaki, S., and M. Yabiku (1984), Channel morphology of the Kali Gandaki and the Narayani rivers in central Nepal, J. Nepal Geol. Soc., 4, 161-176.

Millspaugh, S. H., C. Whitlock, and P. J. Bartlein (2000), Variations in fire frequency and climate over the past 17,000 yr in central Yellowstone National Park, Geology, 28, 211-214.

Minnich, R. A. (1986), Snow levels and amounts in the mountains of southern California, J. Hydrol., 89, 37-58.

Minnich, R. A. (1989), Climate, fire and landslides in southern California, in Landslides in a Semi-arid Environment, With Emphasis on Inland Valley of Southern California, edited by P. M. Sadler and D. M. Morton, Publ. Inland Geol. Soc., 2, 91-100.

Minnich, R. A., and Y. H. Chou (1997), Wildland fire patch dynamics in the chaparral of southern California and northern Baja California, Int. J. Wildland Fire, 7, 221-248.

Molnar, P., and P. England (1990), Late Cenozoic uplift of mountain ranges and global climate change: Chicken or egg?, Nature, 346, 29-34.

Morton, D. M. (1975), Seismically triggered landslides in the area above the San Fernando valley, in San Fernando, California, earthquake of 9 February 1971, Calif. Div. Mines Geol. Bull., 196, 145-154.

Morton, D. M., and J. Matti (1987), The Cucamonga fault zone: Geologic setting and quaternary history, in Recent Reverse Faulting in the Transverse Ranges, California, edited by D. M. Morton and Y. F. Yerkes, U.S Geol. Surv. Prof. Pap., 1339, 179-203.

Morton, D. M., P. M. Sadler, and R. A. Minnich (1989), Large rock-avalanche deposits: Examples from the central and eastern San Gabriel Mountains of southern California, in Landslides in a Semi-arid Environment. With Emphasis on Inland Valley of Southern California, edited by P. M. Sadler and D. M. Morton, Publ. Inland Geol. Soc., 2, 323-337.

Ohmori, H. (1992), Morphological characteristics of the scar created by large-scale rapid mass movement, Jpn. Geomorphol. Union Trans., 13, $185-202$.

Ohmori, H., and M. Hirano (1988), Magnitude, frequency and geomorphological significance of rocky mudflows, land creep and the collapse of steep slopes, Z. Geomorphol. Suppl., 67, 55-65.

Penck, W. (1953), Morphological Analysis of Landforms, 429 pp., St. Martin's, New York.

Petersen, M. D., and S. G. Wesnousky (1994), Fault slip rates and earthquake histories for active faults in southern California, Bull. Seismol. Soc Am., 84, 1608-1649.

Powell, R. E. (1981), Geology of the crystalline basement complex, eastern Transverse Ranges, southern California: Constraints on regional tectonic interpretation, Ph.D. thesis, 441 pp., Calif. Inst. of Technol., Pasadena.

Reneau, S. L., and W. E. Dietrich (1991), Erosion rates in the Southern Oregon Coast Range: Evidence for an equilibrium between hillslope erosion and sediment yield, Earth Surf. Processes Landforms, 16 , $307-322$

Rice, R. M., and G. T. Foggin II (1971), Effect of high intensity storms on soil slippage on mountainous watersheds in southern California, Water Resour. Res., 7, 1485-1496.
Rice, R. M., E. S. Corbett, and R. G. Bailey (1969), Soil slips related to vegetation topography and soils in southern California, Water Resour Res., 5, 647-659.

Rubin, C., S. C. Lindvall, and T. K. Rockwell (1998), Evidence for large earthquakes in metropolitan Los Angeles, Science, 281, 398-402.

Schmidt, K. M., and D. R. Montgomery (1995), Limits to relief, Science, 270, 617-620.

Seeber, L., and V. Gornitz (1983), River profiles along the Himalayan arc as indicators of active tectonics, Tectonophysics, 92, 335-367.

Shen, Z.-K., D. D. Jackson, and B. X. Ge (1996), Crustal deformation across and beyond the Los Angeles basin from geodetic measurements, J. Geophys. Res., 101, 27,957-27,980.

Sheperd, R. G. (1972), Incised river meanders: Evolution in simulated bedrock, Science, 178, 409-411.

Sheperd, R. G., and S. Schumm (1974), Experimental study of river incision, Geol. Soc. Am. Bull., 85, 257-268.

Sieh, K. E., and R. H. Jahns (1984), Holocene activity of the San Andreas fault at Wallace Creek, California, Geol. Soc. Am. Bull., 95, $883-896$.

Sklar, L., and W. E. Dietrich (1998), River longitudinal profiles and bedrock incision modes: Stream power and the influence of sediment supply, in Rivers Over Rock: Fluvial Processes in Bedrock Channels, Geophys. Monogr. Ser., vol. 107, edited by K. J. Tinkler and E. E. Wohl, pp. $237-$ 260, AGU, Washington, D. C.

Slingerland, R., S. Willet, and N. Hovius (1998), Slope-area scaling as a test of fluvial bedrock erosion laws, Eos Trans American Geophysical Union, 79(45), Fall Meet. Suppl., F358.

Snyder, N. P., K. Whipple, G. E. Tucker, and D. Merritts (2000), Landscape response to tectonic forcing: DEM analysis of stream profiles in the Mendocino triple junction region, northern California, Geol. Soc. Am. Bull., 112, 1250-1263.

Spotila, A. J., M. A. House, A. E. Blythe, N. A. Niemi, and G. C. Bank (2002), Controls on the erosion and geomorphic evolution of the San Bernardino and San Gabriel Mountains, southern California, Geol. Soc. Am. Spec. Pap., 365, 205-230.

Stark, C. P., and N. Hovius (2001), The characterization of landslide size distributions, Geophys. Res. Lett., 28, 1091-1094.

Stock, J. D., and D. R. Montgomery (1999), Geologic constraints on bedrock river incision using the stream power law, J. Geophys. Res., 104, 4983-4993.

Tarantola, A. (1987), Inverse Problem Theory, 137 pp., Elsevier, New York. Taylor, B. D. (1981), Sediment management for southern California mountains, coastal plains and shoreline, part B, Inland sediment movement natural processes, Environ. Qual. Lab. Rep.N.17-B, 85 pp., Calif. Inst. of Technol., Pasadena.

Weldon, R. J. (1986), Late Cenozoic geology of Cajon Pass: Implications for tectonics and sedimentation along the San Andreas fault, Ph.D. thesis, $400 \mathrm{pp}$., Calif. Inst of Technol., Pasadena.

Whipple, K. X., and G. E. Tucker (2002), Implications of sediment-fluxdependent river incision models for landscape evolution, J. Geophys. Res., 107(B2), 2039, doi:10.1029/2000JB000044

Wieczorek, G. F. (1987), Effect of rainfall intensity and duration on debris flows in central Santa Cruz Mountains, California, in Debris Flows/ Avalanches: Process, Recognition and Mitigation, edited by J. E. Costa and G. F. Wieczorek, Rev. Eng. Geol., 7, 93-104.

Willett, S. D. (1999), Orogeny and orography: The effects of erosion on the structure of mountain belts, J. Geophys. Res., 104, 28,957-28,981

Willett, S. D., and M. T. Brandon (2002), On steady states in mountain belts, Geology, 30, 175-178.

Willett, S. D., C. Beaumont, and P. Fullsack (1993), Mechanical model for the tectonics of doubly vergent compressional orogens, Geology, 21, $371-372$.

D. Burbank, Department of Geological Sciences, University of California, Santa Barbara, CA 93106, USA. (burbank@crustal.ucsb.edu)

J. Lavé, Laboratoire de Géodynamique des Chaînes Alpines, BP 53 , F-38041 Grenoble, France. (jlave@ujf-grenoble.fr) 